\title{
Cardiac sodium channel, its mutations and their spectrum of arrhythmia phenotypes
}

\author{
Andrés Ricardo Pérez-Riera', Rodrigo Daminello Raimundo, ${ }^{1,2}$, Rodrigo Akira Watanabe ${ }^{3}$, \\ José Luiz Figueiredo ${ }^{1}$, Luiz Carlos de Abreu ${ }^{1,4}$
}

Doi: http://dx.doi.org/10.7322/jhgd.122759

\begin{abstract}
:
The mechanisms of cellular excitability and propagation of electrical signals in the cardiac muscle are very important functionally and pathologically. The heart is constituted by three types of muscle: atrial, ventricular, and specialized excitatory and conducting fibers. From a physiological and pathophysiological point of view, the conformational states of the sodium channel during heart function constitute a significant aspect for the diagnosis and treatment of heart diseases. Functional states of the sodium channel (closed, open, and inactivated) and their structure help to understand the cardiac regulation processes. There are areas in the cardiac muscle with anatomical and functional differentiation that present automatism, thus subjecting the rest of the fibers to their own rhythm. The rate of these (pacemaker) areas could be altered by modifications in ions, temperature and especially, the autonomic system. Excitability is a property of the myocardium to react when stimulated. Another electrical property is conductivity, which is characterized by a conduction and activation process, where the action potential, by the all-or-nothing law, travels throughout the heart. Heart relaxation also stands out as an active process, dependent on the energetic output and on specific ion and enzymatic actions, with the role of sodium channel being outstanding in the functional process. In the gene mutation aspects that encode the rapid sodium channel (SCN5A gene), this channel is responsible for several phenotypes, such as Brugada syndrome, idiopathic ventricular fibrillation, dilated cardiomyopathy, early repolarization syndrome, familial atrial fibrillation, variant 3 of long QT syndrome, multifocal ectopic ventricular contractions originating in Purkinje arborizations, progressive cardiac conduction defect (Lenègre disease), sudden infant death syndrome, sick sinus syndrome, sudden unexplained nocturnal death syndrome, among other sodium channel alterations with clinical overlapping. Finally, it seems appropriate to consider the "sodium channel syndrome" (mutations in the gene of the a subunit of the sodium channel, SCN5A gene) as a single clinical entity that may manifest in a wide range of phenotypes, to thus have a better insight on these cardiac syndromes and potential outcomes for their clinical treatment.
\end{abstract}

Keywords: arrhythmia syndromes, action potential, depolarization, cardiac conduction.

\section{INTRODUCTION}

$\mathrm{NaV} 1.5$ is an integral membrane protein and tetrodotoxin-resistant voltage-gated $\mathrm{Na}+$ channel subunit.

$\mathrm{NaV1.5}$, found primarily in the cardiac muscle, where it mediates the fast infl ux of $\mathrm{Na}+$-ions (INa) across the cell membrane, resulting in the fast depolarization of phase 0 of the cardiac action potential (AP). As such, it plays a major role in impulse propagation. These channels consist of heteromeric assemblies of an $\alpha$-subunit, the pore-forming component, the function of which is modulated by association with one or two ancillary $\beta$-subunits.

The human cardiac $\mathrm{Na}^{+}$channel $\alpha$-subunit is a heavily glycosylated protein of $\approx 260 \mathrm{kDa}$ consisting of 2016 amino acid residues. It is encoded by the SCN5A gene, which is located on chromosome $3 \mathrm{p} 21$. The protein encoded by this gene is an integral membrane protein and tetrodotoxin-resistant voltage-gated sodium channel subunit. This protein is found primarily in the cardiac muscle and is responsible for the initial upstroke phase 0 of the AP in an electrocardiogram.
They display a modular architecture, which consists of four internally homologous domains (DI-DIV) each made up of six transmembrane segments (S1-S6). The interdomain linkers and the $\mathrm{N}$ - and $\mathrm{C}$-terminal ends of the channel protein are all located cytoplasmically. $\mathrm{Na}_{\mathrm{V}}$ 1.5.SCN5A is the gene that encodes the cardiac $\mathrm{Na}^{+}$ channel $\mathrm{Na}_{\mathrm{v}}$ 1.5. Mutations may act as a disease modifier, especially in families where lack of direct causality is reflected by complex inheritance patterns.

A significant amount of individuals $(2-7 \%)$ in the general population carry a rare (population frequency $<1 \%$ ), protein-altering variant in the gene, highlighting the complexity of linking mutations directly with observed phenotypes. Mutations that result in the same biophysical effect can give rise to different diseases. Loss-of-function mutations have been associated with Brugada syndrome (BrS), Progressive Cardiac Conduction Disease (PCCD) or Lenègre disease, variant 3 of long QT syndrome (LQT3), Idiopathic Ventricular Fibrillation (IVF), Early Repolarization Syndromes (ERS), Dilated Cardiomyopathy (DCM), sinus node dysfunction, Sick

1 Design of Studies and Scientific Writing Laboratory at the ABC School of Medicine, Santo André, São Paulo, Brazil.

2 Pos-doctoral. Program in Molecular and Integrative Physiological Sciences Department of Environmental Health. Harvard T H Chan School of Public Health, Boston, USA.

3 Program in Molecular and Integrative Physiological Sciences (MIPS), Department of Environmental Health, Harvard T.H. Chan School of Public Health, Boston, USA.

4 Visiting Scientist. Department of Environmental Health. Harvard T H Chan School of Public Health, Boston, USA. Corresponding author: Andrés Ricardo Pérez-Riera M.D.Ph.D. - E-mail: riera@uol.com.br

Suggested citation: Pérez-Riera AR, Raimundo RD, Watanabe RA, Figueiredo JL, Abreu LC. The cardiac sodium channel its mutations and their spectrum arrhythmia phenotypes. J Hum Growth Dev. 2016; 26(3): 281-296. Doi: http://dx.doi.org/10.7322/jhgd.122759 Manuscript submitted: Received: December, 2015. Modified: June 2016. Accepted: September 2016. 
Sinus Syndrome (SSS), Sudden Infant Death Syndrome (SIDS), Sudden Unexplained Nocturnal Death Syndrome (SUNDS), Familial Atrial Fibrillation (FAF), Multifocal Ectopic Purkinje-related Premature Contractions (MEPPC) and overlapping syndromes or mixed phenotypes. The aim of this study was to contextualize and review the structure of the sarcolemmal channel and the regulation of one of the functional properties of the organ: conductibility or dromotropism along the cardiac structures.

\section{METHODS}

This is a literature review study, the purposes of which are to build a context to the problem and an analysis of the possibilities present in the literature to design the theoretical research framework.

This article was organized from scientific sources available in the database (Pubmed, Scielo, Virtual Health Library, Virtual Library of theses, dissertations) and sources of dissemination of ideas (journals, websites, videos, etc.), with analysis of each material and the development of tests to contextualize, for questioning and an initial validation of the theoretical framework used in research in the field of channel diseases.

Thus, the conceptual analysis is enhanced and it allowed us to establish relationships with previous productions, identifying recurring themes, pointing out new perspectives, consolidating an area of knowledge and constituting didactic and pedagogical practices guidelines for a definition of professional training parameters in the area of Health Sciences and to update the scenario of physiological sciences.

\section{RESULTS AND DISCUSSION}

\section{Sodium channel characteristics}

Voltage-gated $\mathrm{Na}^{+}$channels are transmembrane proteins that produce the ionic current responsible for the rising phase of the cardiac action AP and play a fundamental role in the initiation, propagation, and maintenance of normal cardiac rhythm. The $\mathrm{Na}^{+}$channel has the following functions: it allows conduction of the

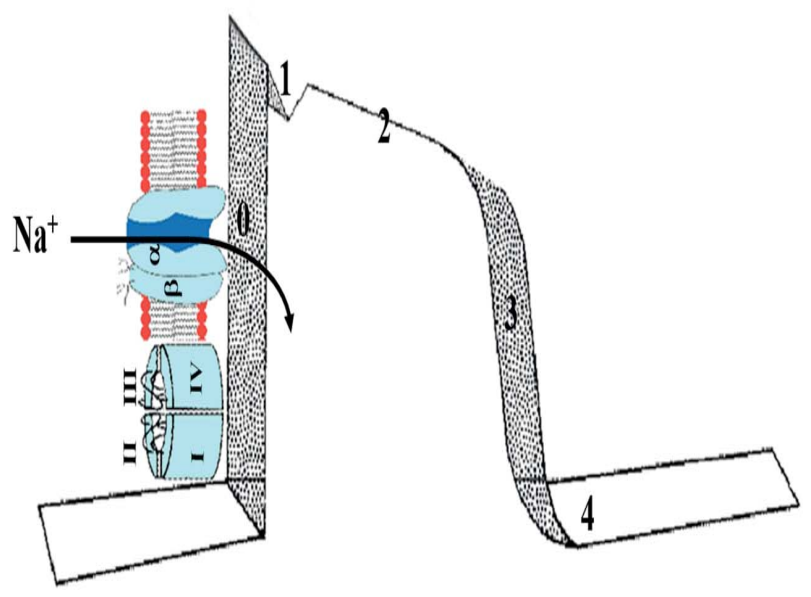

Figure 1: The action potential of a fast fiber, its phase 0 and the entry of the sodium cation by sodium channel. cardiac impulse, excitability, excitation-contraction coupling, and it is the site of action of class IA, IB and IC antiarrhythmic drugs. $\mathrm{Na}^{+}$channels mediate fast depolarization in nerves, skeletal muscle, working myocardium, and in the His-Purkinje system

Voltage-gated $\mathrm{Na}^{+}$channels are essential for the amplitude and upstroke velocity of the cardiac AP, which is an important determinant for impulse propagation, and impulse conduction velocity throughout the working myocardium $^{1}$ (Figure 1).

$\mathrm{Na}^{+}$channel acts on both atrial (P wave) and ventricular (QRS) depolarization. When it is open, $\mathrm{Na}^{+}$enters abruptly into the intracellular medium during phase 0 inverting cell potential (depolarization). Additionally, cardiac contractility largely regulated through transient currents in intracellular $\mathrm{Ca}^{2+}$ concentration $\left[\mathrm{Ca}^{2+}\right]$ i. $\left[\mathrm{Ca}^{2+}\right]$ $i$ is under the influence of the sarcolemmal $\mathrm{Na}^{+} / \mathrm{Ca}^{2+}$ exchanger that exchanges $\mathrm{Ca}^{2+}$ for $\mathrm{Na}^{+}$and which is mainly regulated by the intracellular $\mathrm{Na}^{+}$concentration $\left(\left[\mathrm{Na}^{+}\right]\right.$ i). Consequently, $\left[\mathrm{Na}^{+}\right] \mathrm{i}$ influences cardiac contractility. $\left[\mathrm{Na}^{+}\right] \mathrm{i}$ is regulated by numerous proteins: $\mathrm{Na}^{+} / \mathrm{K}^{+}$ adenosine triphosphates (ATPases), $\mathrm{Na}^{+}-$channels and $\mathrm{Na}^{+} / \mathrm{H}^{+}$exchangers that control and are controlled by $\left[\mathrm{Na}^{+}\right]$ i. In particular, the $\mathrm{Na}^{+} / \mathrm{K}^{+}{ }_{\text {ATPase }}$ and its crosstalk with the other proteins controls the intracellular level of $\mathrm{Na}^{+}$. Evidence suggests that the Several Transport proteins have altered activity and expression patterns and this could partially explain the reduced contractility in heart failure. A better understanding of the control of $\left[\mathrm{Na}^{+}\right]$i may lead to a new therapy for heart failure 2 .

$\mathrm{Na}^{+}$channels are complex molecules of about 240-260 kDa, with the cardiac channel being about $40 \%$ different from the nerve channel ${ }^{3}$.

Rapid depolarization in fast fibers of phase 0 or upstroke of the AP is the sudden reversal of membrane potential that occurs when a normal atrial or ventricular cell reaches threshold potential at -70 to $-55 \mathrm{mV}$.

A normal cardiac cell at rest has a transmembrane potential of -80 to $-95 \mathrm{mV}$ in $\mathrm{Na}^{+}$-channel-dependent fast fibers. The gradient is maintained by pumps, especially $\mathrm{Na}^{+}-\mathrm{K}_{\text {ATPase }}$, and fixed anionic charges within the cell (in this process, amphoteric protein macromolecules are involved). There are both electrical (Table 1) and chemical concentration gradients, which move $\mathrm{Na}^{+}$through resting cell membranes. Table 1 (normal concentration of sodium in extracellular and intracellular fluids); and table 2 (the conduction velocity in the different regions of the heart).

Table 1: Normal concentration of sodium in extracellular and intracellular fluids

\begin{tabular}{cccc} 
ION & EXTRACELLULAR & INTRACELLULAR & RATIO \\
$\mathrm{Na}+$ & $145 \mathrm{mEq} / \mathrm{l}$ & $15 \mathrm{mEq} / \mathrm{l}$ & 9.7 \\
\hline
\end{tabular}

The conduction velocity of fast fibers ( $\mathrm{Na}+$ channel dependent) is between 0.3 to $5 \mathrm{~m} / \mathrm{s}$.

Among cardiac cells, Purkinje fibers have the highest concentration of $\mathrm{Na}^{+}$channels, reaching almost one million per cell ${ }^{4}$. In the cardiac Purkinje fibers, two different populations of $\mathrm{Na}^{+}$channels exist with two different modes of operation for each one: the first is responsible for rapid depolarization, phase 0 or upstroke of AP, and 
Table 2: Conduction velocity in the different regions of the heart

$\begin{array}{lc}\text { Region } & \text { Velocity }(\mathbf{m m} / \mathbf{s}) \\ \text { Central region of the SA node } & 2 \text { to } 5 \\ \text { Peripheral region of the SA node } & 7 \text { to } 11 \\ \text { Internodal bundles } & 1000 \\ \text { Atrial ordinary muscle } & 400 \\ \text { AN region of AV node } & 100 \\ \text { N region of AV node } & 20 \\ \text { NH region of AV node } & 800 \\ \text { His, branches \& Purkinje arborizations } & 4000 \\ \text { Ventricular ordinary muscle } & 400\end{array}$

Table 2 shows different conduction velocities of stimulation in different areas of the heart. The lowest conduction velocity is found in the central region of the SA node (2 to $5 \mathrm{~mm} / \mathrm{s}$ ) and the highest in the His-Purkinje system $(4000 \mathrm{~mm} / \mathrm{s})$. AV: atrioventricular; SA: sinoatrial.

the second, which is longer lasting, participates in phase 2 - steady state or "window" current - as a slow $\mathrm{Na}^{+}$channel type. It was proposed that an overlap between the activation ("m") and inactivation (" $h$ ") variables, which control the $\mathrm{Na}^{+}$conductance, produces a window of slow current during phase 2 of AP, and it is possible that a slow component of inward current exists ${ }^{5}$ (Figure 2 )

Characteristics of the $\mathrm{Na}^{+}$channel. This is a protein structure, formed by four modules that surround a central pore. This channel has a main structure, called $\alpha$ and other surrounding accessory ones called $\beta 1$ and $\beta 2$. This channel is very important in stimulus conduction and cell activation. Inherited mutations in SCN5A, the gene encoding the cardiac $\mathrm{Na}^{+}$channel, provoke life-threatening cardiac arrhythmias, often by modifying these voltage-dependent conformational changes. Nav1.5 consists of four domains (DI-DIV), each containing six transmembrane segments (S1-S6); S4 segments are positively charged and act as voltage sensors.

\section{Sarcolemmal membrane}

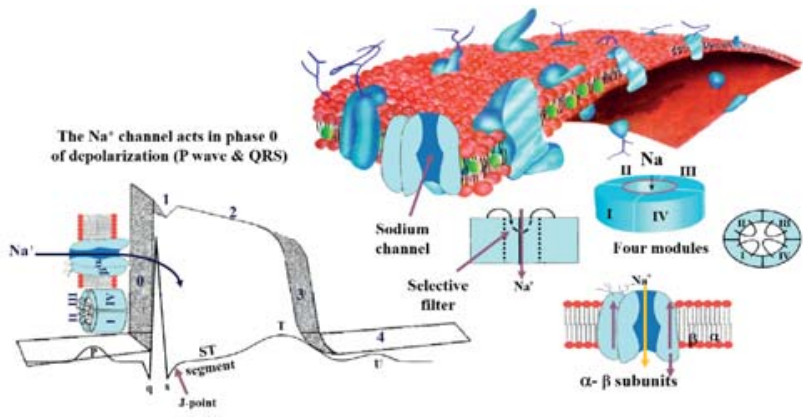

Figure 2: Representation of sarcolemmal membrane. the sodium channel structure and temporal correlation between monophasic action potential and the surface electrocardiogram.

The mean $\mathrm{Na}^{+}$channel density is approximately 200 channels per square micron ${ }^{6}$. Each channel initiates rapid depolarization and contributes to the control of AP duration (APD) by the steady state or "window" current.

In the heart, mediated rapid transmission of excitation through the atria (P wave) and ventricle (QRS) and the delay of AV node enable synchronous ventricular ejection.

The cardiac $\mathrm{Na}^{+}$channel isoform encodes $\mathrm{hH} 1$ and has been mapped to the short arm of chromosome 3 p2124 loci $^{7}$. (Figure 3).

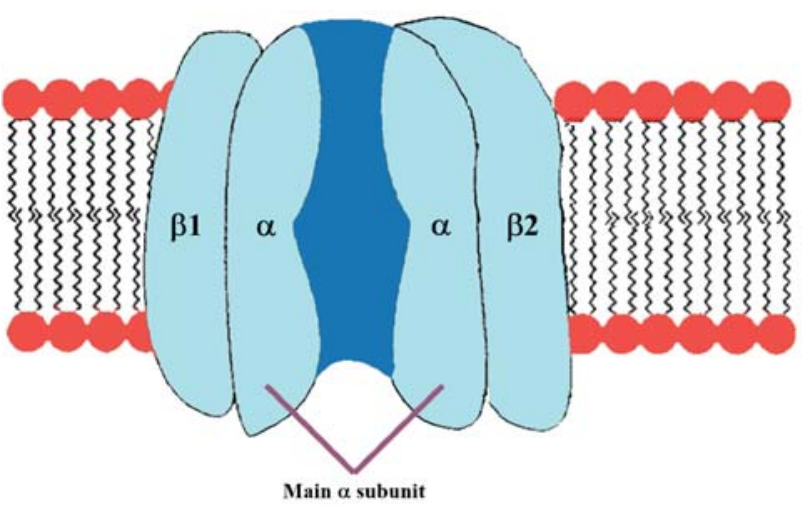

Figure 3: Representation of the sodium channel structure with the main central large $\alpha$ subunit and associated accessory $\beta$ subunits. The $\alpha$ subunit forms the core of the channel and is functional on its own. When the a subunit protein is expressed by a cell, it is able to form channels that conduct $\mathrm{Na}+$ in a voltage-gated way, even if $\beta$ subunits or other known modulating proteins are not expressed. When accessory proteins assemble with $\alpha$ subunits, the resulting complex can display altered voltage dependence and cellular localization.

Molecular structure of the cardiac $\mathrm{Na}^{+}$channel: main $\alpha$-subunit (Nav1.5) and the $-\beta 1-\beta 2$ subunits of the cardiac $\mathrm{Na}^{+}$channel. The $\beta$-subunit consists of one single transmembrane segment. The four domains (DI-DIV) with 6 transmembrane segments (1-6) of Nav1.5 fold around an ion-conducting pore. The expression and function of Nav1.5 is regulated by $\beta$-subunits and several directly or indirectly interacting regulatory proteins and $\beta$ subunits of $\mathrm{Na}^{+}$channels.

\section{Alpha $(\alpha)$ and beta $(\beta)$ subunits}

The genomic organization of the cardiac sodium channel gene (SCN5A) has recently been described.

The three functional states of sodium channel: closed, open, and the inactivated state:

The $\mathrm{Na}^{+}$fast channels have two gates in the gated system hypothesis - designated as "m" (activation) and "h" (inactivation) - and they can assume one of three states: the closed state, the open state and the inactivated state. This hypothetical system ${ }^{8}$ is named to this date as "Hodgkin-Huxley kinetics".

Three " $m$ " activation gates localized on the extracellular side and one " $h$ " inactivation gate on the intracellular side can be considered to be lined up in series in the sarcolemmal membrane.

There are two gates for slow channels: the activation gate ("d") and the inactivation gate ("f") ${ }^{9}$.

\section{Closed or resting state:}

The excitable (resting state) phase of the cell is electrical diastole, during which the " $\mathrm{m}$ " gate is closed and the " $h$ " gate is open; the channel is closed but excitable (" $m$ " is closed and " $h$ " is open). The $\mathrm{Na}^{+}$channels are closed at negative potentials when the cell is in the resting state: $\mathrm{Na}^{+}$does not normally enter resting cardiac cells.

\section{Open state:}

The " $\mathrm{m}$ " gate is the activation gate. A channel is in the open state when the "m" gate opens briefly, which 
occurs when the membrane voltage reaches the threshold potential $(-70 \mathrm{mV})$. This is a voltage-operated channel. At this time there are strong $\mathrm{Na}^{+}$concentrations and electrical gradients that rapidly draw $\mathrm{Na}+$ into the cell (phase 0 of the AP and P or QRS of ECG). This is the threshold for the stimuli to open the $\mathrm{INa}^{+}$channel in response to specific substances interacting with specific receptors on the cell surface. The $\mathrm{Na}^{+}$channel proteins change conformation to a conducting ("open") state and allow up to $10^{7} \mathrm{Na}^{+}$ per second to enter each cell, moving the transmembrane potential toward $\mathrm{ENa}(-65 \mathrm{mV})$.

The "m" gate opens faster than the " $h$ " gate closes, so for about 1 millisecond both gates are open simultaneously. (Figure 4)

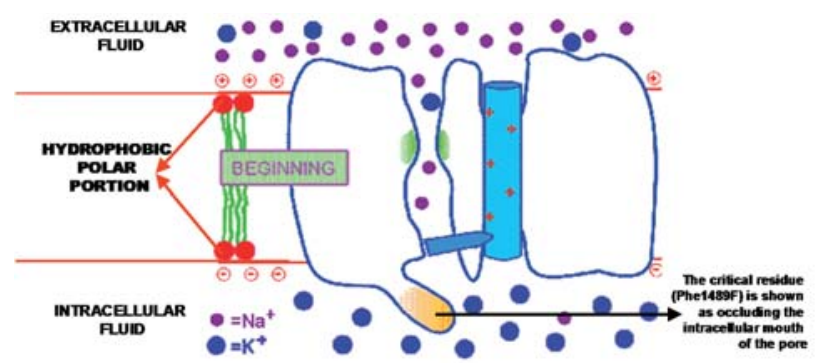

Figure 4: Representation of the sodium (small violet circles) and potassium (large blue circles) movements during action potential (AP). The critical residue Phe-1489 (F) is shown occluding the intracellular mouth of the pore.

\section{Inactivated state:}

The channel is closed but not excitable, from which state the channel cannot open. The voltage-dependent " $h$ " gate closes when the cell becomes positive on the inside. The inactivation of cardiac $\mathrm{Na}^{+}$channel occurs exclusively through the open state ${ }^{10}$.

Note especially that a comparatively small number of $\mathrm{Na}^{+}$ions move into the cell during phase 0 of the AP. The concentration gradient for $\mathrm{Na}^{+}$hardly changes as a result of the AP.

The channel is inactivated and cannot respond to a stimulus until negative voltage is restored when it resumes the rested or closed conformation. The surge of $\mathrm{Na}_{+}$movement lasts only $1 \mathrm{~ms}$ after which the channel protein changes conformation from the "open" state to an "inactivated", that is, non-conducting state. The inactivation of a fast $\mathrm{Na}^{+}$channel is produced by the intracellular loop connecting domains III and IV of a $\mathrm{Na}^{+}$channel and can be thought of as forming a hinged lid.

The critical residue (Phe 1489F) occludes the intracellular mouth of the pore. A cluster of positively charged arginine and lysine residues in the $\mathrm{S} 4$ domain is thought to function as the voltage sensor ("m" gate) while the peptide loop connecting repeats S3 and S4 binds to the activated channel and occludes the intracellular mouth of the channel pore ("h" gate).

The beginning of the inactivated state is partially responsible for phase 1 or rapid repolarization of the AP and the $\mathrm{J}$ point on the ECG.

The remainder of the inactivation process is in phase 2 or "plateau" when a very small but important component of the $\mathrm{Na}^{+}$channel is functioning, prolonging the refractory period. This phase corresponds to the ST segment on an ECG.

The inactivation usually takes place from the open state, but some channels may become inactivated before opening. The $\mathrm{Na}^{+}$channel is voltage-dependent (a voltage-operated channel). The channel opens in response to voltage - a process known as "activation". Since the opening and closing of the gates are voltage and time-dependent, the permeability of the channel $\left(\mathrm{P} \mathrm{Na}^{+}\right)$will be some fraction of the maximum possible permeability $\left(\mathrm{PNa}^{+}\right.$, max) depending on membrane potential and the period that the membrane has been at that voltage. The Figure 5 shows the closed and closed states of the sodium channel.

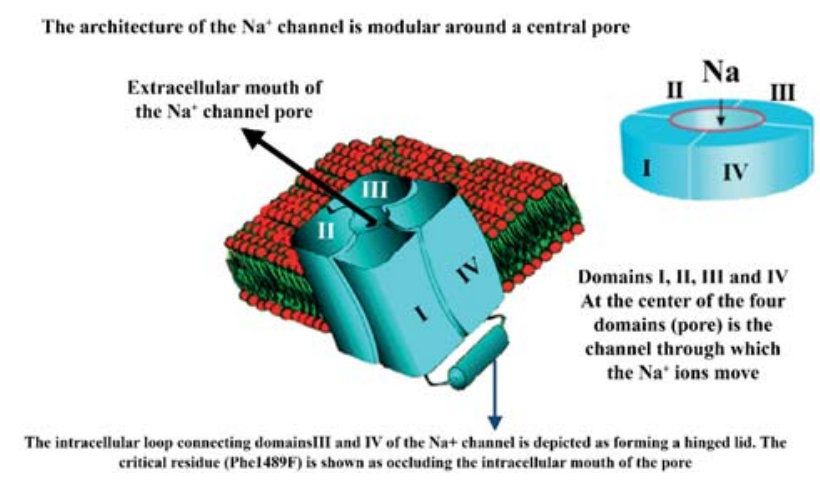

Figure 5: Representation of closed and open states of the sodium channel. The critical residue Phe $1489 \mathrm{~F}$ is shown occluding and opening the intracellular mouth of the pore. Concomitantly, the six membrane spanning subunits, labeled S1 through S6. The highly preserved S4 segment acts as the channel's voltage sensor. The voltage sensitivity of this channel is due to positive amino acids located at every third position. When stimulated by a change in transmembrane voltage, this segment moves toward the extracellular side of the cell membrane, allowing the channel to become permeable to ions.

The predicted secondary structure of the cardiac $\mathrm{Na}^{+}$channel and locations of mutations cause BrS, LQT3, PCCD, overlapping syndromes, AF, and atrial standstill. The channel consists of four putative transmembrane domains (I-IV), with each domain containing six transmembrane segments S1-S6 BrS mutations green triangles, LQT3 red square, Lenègre disease blue circles, overlapping $\mathrm{BrS}$ and Lenègre disease trapezoid pink and black triangle atrial standstill). Three "m" particles control activation:

$$
\mathrm{P}_{\mathrm{Na}}=\mathrm{m}^{3} \cdot \mathrm{h} \cdot \mathrm{P}_{\mathrm{Na}, \mathrm{max}}
$$

The sodium channel has two fundamental properties: ion conduction and gating.

Permeation/Conduction - the mechanism of the selective movement of $\mathrm{Na}^{+}$ions across the pore in the cell membrane. This refers to all the pore properties of the channel, including how ions traverse the channels when they are open. It refers to the ability of a channel to conduct ions once it is open.

Gating - the mechanisms that open and close the sodium channel pore in response to a change in membrane potential. This describes the opening and closing of the sodium channel pore - how channels open and close. We can also say that it is the process whereby channels change 
their conformation in response to an external stimulus inactivation. $\mathrm{Na}^{+}$channel SCN5A gene mutations -apart from changing channel-gating characteristics- may be related to changes in channel protein trafficking and expression. Regulation of ion channel protein expression depends on a fine-tuned balance among various processes: Gene transcription; RNA processing; protein synthesis; assembly and post-translational modification; the transport to the cell surface; the anchoring to the cytoskeleton and; regulation of endocytosis and controlled degradation of the protein.

The channel opens rapidly when the membrane potential reaches the threshold potential: About $-60 \mathrm{mV}$ to $-70 \mathrm{mV}$ in Purkinje fibers. The $\mathrm{Na}^{+}$ionic current in the channel is time-dependent and voltage-gated. The selectivity of the channel for $\mathrm{Na}^{+}$ions is at least 10 times greater than that of other monovalent cations, so the channel is highly selective for $\mathrm{Na}^{+}$ions. The $\mathrm{Na}^{+}$channel does not normally conduct divalent cations. A powerful blocker of $\mathrm{Na}^{+}$entry into the channel is TTX (Tetrodotoxin). Recently a spider cardiotoxin, designated jingzhaotoxin-III (JZTX-III), from the venom of the Chinese spider Chilobrachys jingzhao, showed higher selectivity on Voltage-Gated $\mathrm{Na}^{+}$Channel (VGSCs) isoforms than other spider toxins affecting VGSCs, and the toxin hopefully represents an important ligand for discriminating cardiac VGSC subtypes. Unlike other spider peptides, it contains an uncommon endoproteolytic site (-X-Ser-) anterior to mature protein and the intervening regions of 5 residues, which is the smallest in spider toxin cDNAs identified to date. Under whole cell recording, JZTXIII showed no effects on voltage-gated $\mathrm{Na}^{+}$channels (VGSCs) or calcium channels in dorsal root ganglion neurons, whereas it significantly inhibited tetrodotoxinresistant VGSCs with an IC (50) value of 0.38 microns in rat cardiac myocytes ${ }^{11}$.

The $\alpha$-subunit is a $\approx 2000$-amino acid glycoprotein with four internally homologous domains labeled I to IV. The architecture is modular, with the proteins wrapped around a central pore ${ }^{12}$. Each of these four domains contains six transmembrane segments and resembles a single $\alpha$-subunit of a voltage dependent $\mathrm{K}^{+}$channel.

The pore-lining ("P segment") regions exhibit unusual conservation within a given channel family of like selectivity. The S6 segment of domain IV has been proposed to contain the receptor for local anesthetics, (lidocaine and other "type I" antiarrhythmic drugs) which block the $\mathrm{Na}^{+}$channel in a voltage-dependent manner ${ }^{13}$.

Acute, inflammatory, and neuropathic pain can all be attenuated or abolished by local treatment with $\mathrm{Na}^{+}$ channel blockers such as lidocaine. According to the classic modulated receptor hypothesis, local anesthetics such as benzocaine and lidocaine bind preferentially to fastinactivated $\mathrm{Na}^{+}$channels with higher affinities. However, an alternative view suggests that activation of $\mathrm{Na}^{+}$channels plays a crucial role in promoting high-affinity local anesthetics binding and that fast inactivation per se is not a prerequisite for local anesthetics preferential binding. The $\mathrm{Na}^{+}$channel activation pathway, including most, if not all, transient intermediate closed states and the final open state, promotes high-affinity local anesthetics binding ${ }^{14}$.
The $\mathrm{Na}^{+}$cardiac channel has eight candidate PKA (Protein Kinase A) consensus phosphorylation sites in the II to IV linker of the form KRXXS*, RXXS*, or RXS*. When the channel is phosphorylated by PKA, the wholecell conductance increases. In contrast, PKC (Protein Kinase $C$ ) activity reduces the conductance.

The $\alpha$ subunit of gene SCN5A is sufficient to express a functional channel. Biochemical studies reveal the existence of two distinct $\beta$ - subunits, $\beta-1$ and $\beta-2$, associated with the brain $\mathrm{Na}^{+}$channel.

$\beta$ subunit coexpression increases the level of channel expression and alters voltage-dependent inactivation ${ }^{15}$.

$\mathrm{Na}^{+}$channel $\beta$ subunits are multifunctional molecules that participate in channel modulation and cell adhesion. Reversible, receptor-mediated changes in $\beta 1$ tyrosine phosphorylation modulate its ability to recruit and associate with ankyrin.

\section{$\beta-1$ has two components:}

Tyrosine-phosphorylated $\beta-1$ (pY $\beta-1)$ : $\mathrm{Na}^{+}$channel complexes at intercalated disks of ventricular myocytes are composed of Nav1.5 and pY $\beta-1$, and these complexes are in close association with both $\mathrm{N}$-cadherin and connexin- $43^{16}$;

1) Nonphosphorylated $\beta-1 \mathrm{Na}^{+}$channels isolated from mammalian brain are composed of $\alpha, \beta-1$, and $\beta-2$ subunits. The auxiliary $\beta$ subunits do not form the ion conducting pore, yet play important roles in channel modulation and plasma membrane expression. $\beta-1$ and $\beta-2$ are transmembrane proteins with one extracellular Vset immunoglobulin (Ig) protein domain. It has been shown recently that $\beta-1$ and $\beta-2$ interact with the extracellular matrix proteins tenascin-C and tenascin- $\mathrm{R}^{17}$.

$\mathrm{Na}^{+}$channel $\beta$ subunits modulate channel kinetic properties and cell surface expression levels and function as cell adhesion molecules. $\beta-1$ and $\beta-2$ participate in homophilic cell adhesion resulting in ankyrin recruitment to cell contact sites. Ankyrin recruitment was observed in $\beta-1$ L182 (STOP), showing that residues Ile(166)$\operatorname{Tyr}(181)$ contain the major ankyrin recruiting activity of $\beta-1$. Ankyrin recruitment was abolished in $\beta-1 \mathrm{Y} 181 \mathrm{E}$, suggesting that tyrosine phosphorylation of $\beta-1$ may inhibit $\beta$-1-ankyrin interactions. Ankyrin (G) and $\beta-1$ associate in rat brain membranes and in transfected cells expressing $\beta-1$ and $\operatorname{ankyrin}(\mathrm{G})$ in the absence of $\mathrm{Na}^{+}$ channel $\alpha$ subunits. $\beta-1$ subunits are recognized by antiphosphotyrosine antibodies following treatment of these cell lines with fibroblast growth factor $\beta-1$ and ankyrin $(\mathrm{G})$ association is not detectable in cells following treatment with fibroblast growth factor. Ankyrin $(\mathrm{G})$ and $\beta-1 \mathrm{Y} 181 \mathrm{E}$ do not associate even in the absence of fibroblast growth factor treatment. $\beta-1$ subunit-mediated cell adhesion and ankyrin recruitment may contribute to $\mathrm{Na}^{+}$channel placement at nodes of Ranvier. The phosphorylation state of $\beta$-1Y181 may be a critical regulatory step in these developmental processes ${ }^{18}$.

Subunits may be differentially localized in the heart and thus interact with different cytoskeletal and signaling proteins. 
$\beta-1$ phosphorylation appears to regulate its localization to differential subcellular domains. It is a guanidinium with high affinity by an aromatic residue in the $P$ region of domain I in position 373 in the $\mathrm{hH} 1$ sequence.

\section{Drugs that affect the $\mathrm{Na}^{+}$channel}

Other substances including local anesthetics and antiarrhythmic agents Class IA, IB and IC have TTX-like $\mathrm{Na}^{+}$channel blocking properties ${ }^{19}$.

Class IA antiarrhythmics - Ajmaline, quinidine, procainamide and disopyramide phosphate - show intermediate rapidity dissociation kinetics from the $\mathrm{Na}^{+}$channel. These drugs have an intermediate kinetics greater than 1 but less than 5 seconds. They reduce the $\mathrm{V}_{\max }$ (slow conduction) and prolong the AP duration (APD). Ajmaline differs only in the His-Purkinje system, causing a significant shortening of the dome, plateau or phase 2 of AP.

Class I antiarrhythmic agents ajmaline and procainamide produce accentuation of ST elevation in patients with $\mathrm{BrS}$, and have been shown to be effective in unmasking BrS when concealed, transitory or intermittent.

Ajmaline is used through IV access, in a $10 \mathrm{mg}$ dose each two minutes, until it reaches a $1-\mathrm{mg} / \mathrm{kg} \mathrm{dose} \mathrm{d}^{20}$. A prolongation of $>30 \%$ of the QRS complex, and the appearance of a typical type 1 Brugada pattern or premature ventricular contractions, are considered events that indicate the end of the test.

The responses could be varied:

1) In approximately 20 to $25 \%$ of the cases, a typical coved ST segment elevation at least $2 \mathrm{~mm}$ and $80 \mathrm{~ms}$ in duration from the $\mathrm{J}$ point in at least two right precordial leads or from $\mathrm{V}_{1}$ to $\mathrm{V}_{3}$, which means the test is positive for $\mathrm{BrS}$. In a patient with ECG that suffered aborted SCD or syncope, without structural heart disease, if ajmaline causes this ECG pattern, ICD implantation is indicated ${ }^{21 ; 22 ; 23}$. Schmidt et al, report a 20-year-old patient suffering cardiopulmonary resuscitation due to VF. The authors diagnosed $\mathrm{BrS}$ after ruling out structural heart disease and a positive ajmaline test and implanted an ICD. It was found that one brother and one sister presented the beginning of RV dilatation and a fibrolipomatous area in the anterior wall segment of the RV compatible with "concealed" ARVC/D. The case report demonstrates the value of familiar examination of patients with an unclear ventricular arrhythmogenic event ${ }^{24}$. In order to examine a possible link between ARVD/C and BrS, systematic ajmaline testing with $1 \mathrm{mg} / \mathrm{kg}$ body weight intravenously, was performed by Peters et al ${ }^{25}$ in 55 patients with ISFC/European Society of Cardiology criteria ${ }^{26}$ of ARVC/D. In nine patients' ajmaline testing demonstrated type $1 \mathrm{BrP}$ in the right precordial leads. The authors concluded that these observations with systematic ajmaline testing demonstrate a definite link between ARVC/D and BrS. We disagree with these conclusions. We would argue that this result could also be interpreted to indicate that the ajmaline test is not specific for uncovering BrS. A positive test is observed with ajmaline in cases of Chagasic myocarditis, a parasitic cardiomyopathy, as well as with a wide variety of $\mathrm{Na}^{+}$channel blockers in the acquired form of the syndrome ${ }^{27}$.

2) There is a reference to the appearance of extreme deviation of SÂQRS to the left in the frontal plane, concomitant with ST segment elevation. The phenomenon probably reflects a left anterior fascicular block due to the predominant effect of the drug on the His-Purkinje system ${ }^{28}$. The test may differentiate the cases of ARVD/C, where the use of class IA antiarrhythmic agents, ajmaline and procainamide (ajmaline $1 \mathrm{mg} / \mathrm{kg}$ ), procainamide $(10 \mathrm{mg} / \mathrm{kg}$ ) or class IC (flecainide $2 \mathrm{mg} / \mathrm{kg}$ ) does not cause ST segment elevation. In some patients previously classified as having IVF, the test of ajmaline or procainamide unmasks the typical ECG BrP, suggesting that this incidence could be higher than what was suspected previously ${ }^{29}$;

3) In the IV test of ajmaline in BrS, concomitantly with ST segment elevation in the right precordial leads, a delay is observed in the zero phase (upstroke) of the monophasic AP (MAPs) exclusively or more pronounced in the RVOT ${ }^{30}$;

4) Symptomatic VT (rare, less than 1.5\%)

5) Monomorphic VT has been described after injection of ajmaline in $\mathrm{BrS}$ patients ${ }^{31}$;

6) In patients carriers of $\mathrm{BrS}$, the area estimated of ST segment elevation, using body surface potential mapping, in the presence of posterior potentials and certainty at PES, constitutes a valuable noninvasive marker in risk stratification; and when ajmaline is used, this estimated area of ST segment elevation increases even more;

7) Using body surface potential mapping, it was observed that in the left precordial leads, the patients with BrS showed the mirror or reciprocal image of the shifts occurred in the right precordial leads, and these shifts are increased when ajmaline is used;

8) ST segment elevation has rarely been observed from $V_{1}$ to $V_{2}$ without arrhythmias, which may mean silent ischemia not detected previously, transmural dispersion of conduction and refractoriness in the RV outflow tract or HR-dependent $\mathrm{Na}^{+}$channel block;

9) In patients with normal baseline ECG, approximately $2 \%$ of the cases, the test results positive. The test is indicated in all patients that suffered aborted SCD or unexplained syndrome, without structural heart disease, in whom the ECG would not spontaneously show the typical ECG Brugada pattern. Also, in the relatives of the affected patients. The test with this drug in BrS is considered a very useful tool.

Class IB antiarrhythmic agents - Mexiletine, phenytoin, tocainide, lidocaine, and apridine - show rapid dissociation kinetics from the $\mathrm{Na}^{+}$channel $(<500 \mathrm{~ms})$. These drugs do not reduce $\mathrm{V}_{\max }$. and shorten $\mathrm{APD}^{32}$. The QRS 
duration and JT interval are not prolonged with these drugs, however mexiletine has a rate-dependent blocking effect on $\mathrm{Na}^{+}$channel that might be intensified under hyperkalemia ${ }^{33}$. They have little effect on the APD and conduction in normal tissues but would depress the conduction of closely coupled premature ventricular contractions (PVCs) as well as partially depressed cells. These drugs have dissociation time constants of less than 1 second.

Drugs with fast-blocking kinetics of interaction with the $\mathrm{Na}^{+}$channel may have a selective effect on conduction during tachycardia. Mexiletine decreases QTc interval as well as dispersion of repolarization in LQT3 syndrome but has no effect on $\mathrm{BrS}^{34}$. Mexiletine is used for ventricular arrhythmias but is also found to be effective for paramyotonia congenita, potassium-aggravated myotonia, LQT3 variant of congenital LQTS and neuropathic pain. Efficacy of mexiletine is primarily due to the openchannel block of persistent late $\mathrm{Na}^{+}$currents, which may arise during various pathological conditions ${ }^{35}$. Mexiletine, is most effective in abbreviating QT interval in LQT3, but effectively reduces transmural dispersion of repolarization (TDR) and prevents the development of Torsade de Pointes (TdP) in all classical 3 models: LQTS, suggesting its potential as an adjunctive therapy in LQT1 and LQT2 ${ }^{36}$.

Chang et $\mathrm{al}^{37}$ described a novel, spontaneous LQT3 mutation identified in the transmembrane segment 6 of domain IV of the $\mathrm{Na}(\mathrm{v}) 1.5$ cardiac $\mathrm{Na}^{+}$channel, with a G-->A substitution at codon 1763, which changed a valine (GTG) to a methionine (ATG). The patient was a newborn with fetal bradycardia, 2:1 atrioventricular block and VT soon after birth. The 2:1 atrioventricular block improved to $1: 1$ conduction only after intravenous lidocaine infusion or a high dose of mexiletine, which also controlled the VT. The $\mathrm{Na}(\mathrm{v}) 1.5 / \mathrm{V} 1763 \mathrm{M}$ channel dysfunction and possible neighboring mutants contribute to a persistent inward current due to altered inactivation kinetics and clinically congenital LQTS with perinatal onset of arrhythmias that responded to lidocaine and mexiletine.

Class IC antiarrhythmics - Flecainide, pilsicainide, propafenone, encainide, moricizine and lorcainide - show dissociation kinetics in the $\mathrm{Na}^{+}$channel (10 to 20 seconds). These drugs reduce $V_{\max }$ and can minimally increase the refractoriness index, which is based on the ratio between the relative refractory period and the APD.

Flecainide acetate: Class IC drugs produce markedly slower conduction but have little effect on the APD. Flecainide is an antiarrhythmic agent that belongs to the class IC of the Vaughan Williams classification, which causes a potent inhibition on the $\mathrm{Na}^{+}$channel by possessing a slow binding and dissociation kinetics with this channel (10 seconds to 30 seconds). The data indicate that flecainide rapidly gains access to its binding site when the channel is open and inhibits $\mathrm{Na}^{+}$channel by a pore blocking mechanism. Closing of either the activation or the inactivation gate traps flecainide within the pore resulting in the slow recovery of the drug-modified channels at hyperpolarized voltages ${ }^{38}$. Other channels affected by the drug are the $I_{\text {tol }}$ channel in therapeutic concentrations and rate-independent; the $\mathrm{I}_{\mathrm{Ca}}{ }^{2+}$ channel in high concentrations and the fast rectifier potassium channel $\mathrm{I}_{\mathrm{Kr}}$ in a voltage-dependent fashion.
A low dose of oral flecainide shortens the QTc interval and normalizes the $\mathrm{T}$ wave repolarization pattern in patients with the LQT3 variant with the DeltaKPQ mutation of SCN5A. The DeltaKPQ mutation presents repetitive reopening of $\mathrm{Na}^{+}$channel and a slow and prolonged cation-entrance current in phase $2^{39}$. Thus, flecainide in low doses is a promising therapeutic agent for patients with LQTS with the DeltaKPQ mutation of SCN5A in the $\mathrm{Na}^{+}$channel. It was verified that only flecainide (and not lidocaine) corrects the LQT3 phenotype in DG mutation carriers.

These results prove that this mutation confers a unique pharmacological response in the expression of the channels, and it is known that the DG channels block by flecainide acts on the C-terminal of the $\alpha$ subunit of the $\mathrm{Na}^{+}$channel by a flecainide/channel interaction. Association of oral flecainide with ICD could be effective in the LQT3 variant. Harkel et $\mathrm{al}^{40}$ presented a case in which LQTS induced severe prenatal and neonatal arrhythmias. LQT3 was diagnosed (mutation R1623Q).

Short-acting $\beta$-blockers were ineffective as well as sotalol and mexiletine in preventing recurrent ventricular arrhythmias. An ICD was implanted at the age of 7 months (weight and length of the infant at implantation $6 \mathrm{~kg}$ and $60 \mathrm{~cm}$ respectively). Flecainide was prescribed in addition to the ICD implantation. After an appropriate shock the flecainide plasma levels were shown to be sub-therapeutic. Readjustment of the flecainide dose resulted in adequate plasma levels. No further shocks occurred during a further 17 months' follow-up period. The combination of an active can with a subcutaneous patch proved feasible, and lifesaving shocks occurred at 7 months after implantation.

Clinical management of LQT-3 and diagnosis of $\mathrm{BrS}$ with the local anesthetic flecainide has proven promising. Channels associated with LQT-3 (D1790G) and BrS (Y1795H) both show more sensitivity to flecainide than wild-type (WT) channels, while lidocaine sensitivity is unchanged. One plausible explanation for differential drug sensitivity is that mutant channels may allow more access to a receptor site compared with wild-type through altered protein allosteric changes during action potential. The high affinity binding site for local anesthetic block has been identified in the pore region of the channel. This region is not water accessible during the closed state, thus requiring channel opening for charged drug (flecainide and mexiletine) access and block. Channel mutations which disrupt inactivation biophysics lead to increased drug binding by altering the time the binding site is accessible during an AP. Neutral drugs (lidocaine) which are not dependent on channel opening for binding site access will not be sensitive to mutations that alter channel inactivation properties. Interestingly another LQT-3 mutant (Y1795C) shows no change in flecainide sensitivity, suggesting that although drug effects of SCN5A mutations cross disease boundaries, clinical management with flecainide will be beneficial to patients in a mutation-specific manner ${ }^{41}$.

Flecainide has a predominant negative dromotropic effect in high rates and more intense than class IA drugs, which may involve ventricular performance in patients with ejection fraction previously affected. 
These agents have the slowest dissociation rate: greater than 12 seconds. QRS widening may be observed at therapeutic levels of drug concentration. The incidence of proarrhythmic response appears highest with this class of drugs because the half time of recovery is greater. It shortens AP in Purkinje fibers (probably by delayed gating $\mathrm{Na}^{+}$channel block) and on the contrary, it prolongs AP in the muscle fibers of ventricles and atria (possibly by block of delayed rectifier currents ${ }^{42}$. In the latter, the drug prolongs AP significantly at high heart rates; unlike quinidine that prolongs AP at slow rates ${ }^{43}$. Flecainide and quinidine increase AP duration (APD) in the human atrial tissue; however, with an opposite dependence on HR. The effect of the drug increasing APD and refractoriness at high rates is very useful in AF reversion with a high rate of ventricular response. The mechanism by which it acts reversing AF is by prolonging that of the atria.

Class IA and IC antiarrhythmic drugs increase STsegment elevation and predilection for PVT and VF in $\mathrm{BrS}$, whereas these agents shorten the repolarization and QT(c) interval. Arrhythmias are suppressed by mexiletine, for the late persistent $\mathrm{Na}^{+}$channel ${ }^{44}$ and thus may be beneficial in LQT3 syndrome.

An area of possible crucial application of the molecular genetic of cardiac ion channels, is the so-called drug-induced TdP and acquired LQTS. This condition is defined as an abnormal response to the administration of a variety of drugs which, in susceptible subjects, may induce an excessive QT interval prolongation and possibly lead to the onset of life-threatening ventricular tachyarrhythmias (drug-induced TdP). The "proof of concept" that sub-clinical variants of the inherited LQTS may play a causative role has been recently brought to light. However, large population-based studies are still needed in order to quantify the epidemiological relevance of such findings. The future developments in this area of research will lead to the availability of pre-prescription genotyping for the identification of the susceptible subjects and to the development of safer drugs ${ }^{45}$.

\section{Sodium channelopathies: the different pheno- types of the SCN5A mutation ${ }^{46}$}

Several families of mutations have been identified in SCN5A, the gene that encodes the human cardiac $\mathrm{Na}^{+}$ channel $\alpha$-subunit (hH1). Inherited mutations in SCN5A, the gene encoding the pore-forming subunit of the cardiac $\mathrm{Na}+$ channel, have been associated with distinct cardiac rhythm syndromes.

Mutations in the cardiac $\mathrm{Na}^{+}$channel can lead to several clinical arrhythmogenic disorders with SCD and epileptic tendency ${ }^{46}$.

Mutations in SCN5A lead to a broad spectrum of phenotypes, however the SCN5A gene is not commonly involved in the pathogenesis of BrS and associated disorders ${ }^{47}$. Studies have revealed significant overlap between aberrant rhythm phenotypes, and single mutations have been identified that evoke multiple rhythm disorders with common gating lesions. These new insights enhance understanding of the structure-function relationships of voltage-gated $\mathrm{Na}^{+}$channels, and also highlight the com- plexities involved in linking single mutations, ion-channel behavior, and cardiac rhythm.

The biophysical characterization of the $\mathrm{Na}^{+}$channelopathies associated with different phenotypes and the genotype-phenotype correlation studies brought to the attention of the scientific community a plethora of mechanisms by which even a single amino acid substitution may remarkably affect cardiac rhythm. The evidence of patients harboring an SCN5A mutation and overlapping clinical presentations creates a need for a revision of the traditional classification of mentioned channelopathies ${ }^{48}$.

It is appropriate to consider the " $\mathrm{Na}^{+}$channel syndrome" as a unique clinical entity that may manifest itself with a spectrum of possible phenotypes ${ }^{49}$.

The known phenotypes are:

1) Congenital long-QT syndrome variant 3 (LQT3) associated with an increased incidence of TdP and SCD. The mutation in SCN5A causing LQTS leads to gain of function with delayed inactivation of the channel resulting in prolonged AP and ST segment and late onset $\mathrm{T}$ wave on ECG. In LQTS, ion channel mutations cause a preferential prolongation of the $\mathrm{M}$ cell AP that contributes to the development of long QT intervals, a large transmural dispersion of repolarization, which provides the substrate for the development of TdP. An early afterdepolarization-induced triggered beat is thought to provide the PVC that precipitates $\mathrm{TdP}^{49}$. Mexiletine is effective in reducing dispersion of repolarization and preventing TdP in LQT2 and LQT3 models ${ }^{50}$.

2) Brugada syndrome: It is characterized by ECG findings of J point and ST elevation $\geq 2 \mathrm{~mm}$ in the right precordial leads followed by negative $\mathrm{T}$ wave called type 1 Brugada pattern $(\mathrm{BrP})$. Mutations in the SCN5A gene known to cause $\mathrm{BrS}$ in $\approx 20 \%$ of cases are thought to be loss of function of the $\mathrm{Na}^{+}$channel. It is the basis of the BrS clinical phenotype ${ }^{51}$. When related to the SCN5A gene, the loss of function of cardiac $\mathrm{Na}^{+}$channels, either by reducing expression levels or by increasing its inactivation kinetics, is the main pathological origin of BrS. ECG findings are not always present and may be triggered by $\mathrm{Na}^{+}$channel antagonists. Mutations in other genes have not been identified, and it is not known if the efficacy of drug testing or the malignancy of arrhythmias correlates to the gene defect. A study identifies an expression-defective BrS mutation in SCN5A with pharmacological rescue. Valdivia et al. identified an expression-defective $\mathrm{BrS}$ mutation in SCN5A with pharmacological rescue. The profoundly decreased $\mathrm{Na}^{+}$current associated with G1743R suggests a molecular basis for the delayed His-Purkinje conduction and elevated high defibrillation thresholds observed in the proband. Whether the mutant channel may be rescued in vivo by mexiletine and normalize the patient's electrophysiological parameters remains to be tested ${ }^{52}$. (Figure 6) 


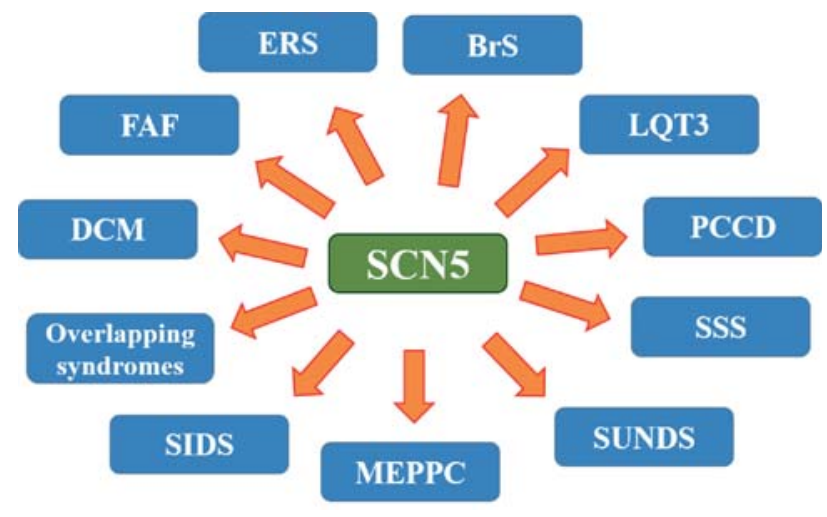

Figure 6: Representation of numerous phenotypes consequence of SCN5A gene mutations: Early repolarization syndrome (ERS); Brugada syndrome $(\mathrm{BrS})$; Congenital long QT syndome variant 3 (LQT3); Progressive Cardiac Conduction Disease (PCCD) or Lenègre disease; Sick Sinus Syndrome (SSS); Sudden Unexplained Nocturnal Death Syndrome (SUNDS); Multifocal Ectopic Purkinje-related Premature Contractions (MEPPC); Sudden Infant Death Syndrome (SIDS); Overlapping syndromes; Dilated Cardiomyopathy (DCM); and Familial Atrial Fibrillation (FAF).

It is appropriate to consider the " $\mathrm{Na}^{+}$channel syndrome" (mutations in $\mathrm{Na}^{+}$channel $\alpha$-subunit gene SCN5A) as a unique clinical entity that may manifest itself with a broad spectrum of possible phenotypes. Mutations in the $\mathrm{Na}^{+}$channel gene SCN5A are found in $\approx 20 \%$ of cases while mutations in other genes collectively account for $<5 \%$. Ion channel dysfunction, in particular in the cardiac $\mathrm{Na}^{+}$channel, may not be a prerequisite for BrS.

3) Some Sudden Infant Death Syndrome cases: $\mathrm{BrS}$ has been linked to the sudden infant death syndrome (SIDS) by showing that the ECG and mutations are the same as in BrS. Approximately $2 \%$ of prospective, population-based cohort of SIDS cases had an identifiable SCN5A channel defect, suggesting that mutations in cardiac ion channels may provide a lethal arrhythmogenic substrate in some infants at risk for SIDS 53; 54;

4) Some Sudden Unexplained Nocturnal Death Syndrome (SUNDS) ${ }^{55}$;

5) Idiopathic ventricular fibrillation without typical ECG findings of $\mathrm{BrS}^{56}$

6) Progressive cardiac conduction disease or Lenègre disease conduction block. PCCD is defined by isolated prolongation of the conduction parameter in the His-Purkinje conduction system but no ST-segment elevation or QT prolongation. It is also associated with a risk of complete atrioventricular block and StokeAdams syncope. The pathophysiology sequence of PCCD results from a loss-of-function of the cardiac $\mathrm{Na}^{+}$channel ${ }^{57}$;

7) Mixed forms: LQT3 and $\mathrm{BrS}^{58}$; overlapping clinical features of $\mathrm{BrS}$ and cardiac conduction disease. The same mutation in the SCN5A gene can lead either to $\mathrm{BrS}$ or to an isolated cardiac conduction defect ${ }^{59}$. Weiss et al, described a large multigenerational family with an autosomal dominant form of $\mathrm{BrS}$ associated with pro- gressive conduction disease, a low sensitivity to procainamide testing, and a relatively good prognosis in a single large pedigree, age- and sex-dependent. Linkage to a locus on chromosome 3p22-25 distinct from SCN5A is identified, confirming genetic heterogeneity of the disorder. The low incidence of SCD in this family and the relative resistance to $\mathrm{Na}^{+}$channel-blocking agents raise the possibility that the efficacy of diagnostic and therapeutic interventions may be gene-dependent ${ }^{60}$. It is named $\mathrm{BrS}$ type 2.

LQT3, BrS and conduction system disease linked to a single $\mathrm{Na}^{+}$channel mutation was reported by Grant et al. The authors have identified a four-generation family, including 17 gene carriers with LQT3, BrS, and conduction system disease with deletion of lysine 1500 (DeltaK1500) within the linker. The late component of $\mathrm{Na}^{+}$current was increased in the DeltaK1500 mutant channel. These changes can account for the complex phenotype in this kindred and point to an important role of the III/IV linker in channel activation ${ }^{61}$;

Congenital long QT syndrome with 2/1 atrioventricular block ${ }^{62}$;

Rossenbacker et al described a novel pore mutation, $\mathrm{R} 376 \mathrm{H}$, in the first pore segment of SCN5A that variably causes $\mathrm{BrS}$ and/or conduction disease in a single family. The phenotype in the family members is highly variable and ranged from non-inducible and inducible asymptomatic carriers of the mutations to isolated conduction disease and to symptomatic BrS. Recognition of factors modifying the clinical presentation may be important for clinical decision making ${ }^{63}$.

A novel human $\mathrm{Na}^{+}$channel mutation, (SCN5A) E161K was identified by Smits et al., in individuals of two non-related families with symptoms of bradycardia, sinus node dysfunction, generalized conduction disease and $\mathrm{BrS}$, or combinations thereof. A loss of $\mathrm{Na}^{+}$channel function is not only associated with $\mathrm{BrS}$ and conduction disease, but may also cause sinus node dysfunction in carriers of this mutation ${ }^{64}$;

8) Congenital epilepsy ${ }^{65}$;

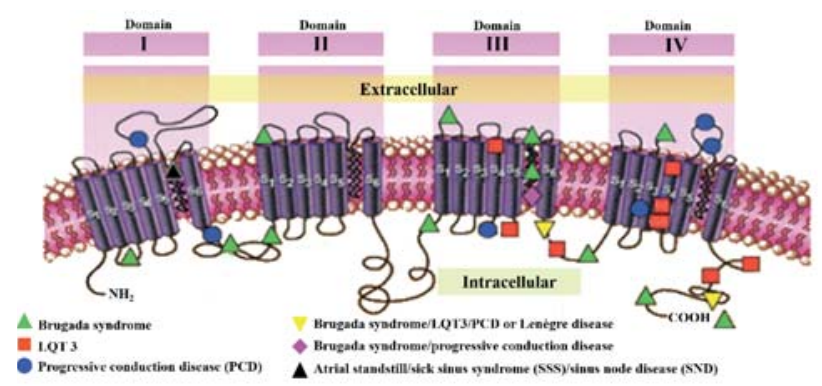

Figure 7: Shows the point of mutation in the diverses phenotypes: green triangle Brugada syndrome; yellow triange overlappying BrS, LQT3 or Lenegre disease; red square: LQT3; blue circle PCCD or Lenègre disease; Purple diamond shape BrS/PCCD; black triangle: SSS/SND or atrial standstill. 
In $\mathrm{BrS}$ the site of the mutations is different than that of chromosome 3-linked congenital LQT3 and does not result in a prolonged QT interval. LQT3 and BrS due to the SCN5A gene seem to be electrophysiological mirror images with LQTS due to gain of function and BrS due to loss of function. Coexistence of these syndromes is seemingly paradoxical; LQT3 is associated with gain in $\mathrm{Na}^{+}$channel function, and $\mathrm{BrS}$ with reduced function. The 1795insD mutation can cause both LQT3 and BrS through interaction with the heterogeneous myocardium in a ratedependent manner. The results highlight the complexity and multiplicity of genotype-phenotype relationships, and the usefulness of computational approaches in establishing a mechanistic link between genetic defects and functional abnormalities ${ }^{66}$. The substitution (D1790G) causes LQTS and the insertion (D1795) induces both LQT3 and $\mathrm{BrS}$ in carrier patients ${ }^{67}$. For both D1790G and insD1795, there is a persistent inward $\mathrm{Na}^{+}$current of about $6 \%$ at -30 $\mathrm{mV}$. In addition, there is a $62 \%$ reduction of channel expression for the insD1795. hH1/ins D1795 and hH1/D1790G mutant channels were expressed in the tsA201 human cell line and it was functionally characterized using the patch clamp technique in whole-cell preparation.

D1790G (DG), an LQT3 mutation of the C-terminal region of the sodium channel $\alpha$-subunit, alters steadystate inactivation of expressed channels but does not promote sustained sodium channel activity ${ }^{68}$.

The C-terminus of $\mathrm{Na}(\mathrm{v}) 1.8$ contributes to regulation of channel density at the cell surface, modulates channel gating, and regulates the generation of sustained current $t^{69}$.

Other sodium channel mutations observed in $\mathrm{BrS}$ and LQT3 include the R1512W mutation (producing a slowing of both inactivation and recovery from inactivation) and the R4132G mutation, respectively. The E1784K mutation found in LQT3 showed persistent inward $\mathrm{Na}^{+}$ current, a hyperpolarized shift of the steady-state inactivation, and a faster recovery from inactivation ${ }^{70}$.

Paradoxically, an inherited C-terminal SCN5A mutation causes affected individuals to manifest ECG features of both syndromes: QT-interval prolongation (LQT3) at slow heart rates and distinctive ST-segment elevations $(\mathrm{BrS})$ with exercise. The insertion of the amino acid $1795 \mathrm{insD}$ has opposite effects on two distinct kinetic components of $\mathrm{Na}^{+}$channel gating (fast and slow inactivation) that render unique, simultaneous effects on cardiac excitability. The mutation disrupts fast inactivation, causing sustained $\mathrm{Na}^{+}$current throughout the AP plateau and prolonging cardiac repolarization at slow heart rates ${ }^{71}$. At the same time, $1795 \mathrm{insD}$ augments slow inactivation, delaying recovery of $\mathrm{Na}^{+}$channel availability between stimuli and reducing the $\mathrm{Na}^{+}$current at rapid heart rates.

Research has revealed a novel molecular mechanism for $\mathrm{BrS}$ and identified a new dual mechanism whereby single SCN5A mutations may evoke multiple cardiac arrhythmia syndromes by influencing diverse components of the $\mathrm{Na}^{+}$channel gating function ${ }^{72}$.

A calcium sensor Calmodulin (CaM), a ubiquitous $\mathrm{Ca}^{2+}$ sensing protein, binds to the carboxy-terminal 'IQ' domain of the human cardiac $\mathrm{Na}^{+}$channel $(\mathrm{hH} 1)$ in a $\mathrm{Ca}^{2+}$ dependent manner. This binding interaction significantly enhances slow inactivation-a channel-gating pro- cess linked to life-threatening idiopathic ventricular arrhythmias. A mutation (A1924T) in the IQ domain altered $\mathrm{hH} 1$ function in a manner characteristic of the Brugada arrhythmia disease, but at the same time inhibited slow inactivation induced by $\mathrm{Ca}^{2+} / \mathrm{CaM}$, yielding a clinically benign phenotype ${ }^{73}$.

The cardiac ryanodine receptor (RyR) is the sarcoplasmic reticulum (SR) Ca-release channel that is involved in the myocyte excitation-contraction, coupling process and certain cardiac arrhythmias, and even contributes to pacemaker activity in the heart. The RyR is also the center of a massive macromolecular complex, which includes numerous regulatory proteins, which can modulate RyR function. This complex includes proteins that interact with the cytoplasmic part of the RyR directly or indirectly: calmodulin (CaM), FK-506-binding proteins, protein kinase $\mathrm{A}, \mathrm{Ca}-\mathrm{CaM}-d e p e n d e n t$ protein kinase, phosphatases 1 and 2A, mAKAP, spinophilin, PR130, sorcin, triadin, junctin, calsequestrin and Homer. Information is evolving in terms of understanding both the physical/ molecular nature of the protein-protein interactions between RyR and these other proteins ${ }^{74}$. The use of class $1 \mathrm{C}$ antiarrhythmic drugs flecainide and pilsicainide causes an increase in ST segment elevation in right precordial leads and the inferior wall, resembling inferior ischemia ${ }^{75}$.

$\mathrm{Na}^{+}$channel blockade by antiarrhythmic drugs improves the QT interval prolongation in LQT3 but worsens BrS ST-segment elevation. Although $\mathrm{Na}^{+}$channel blockade has been proposed as a treatment for LQT3, flecainide also evokes "Brugada-like" ST-segment elevation in LQT3 patients. Low-dose, oral flecainide consistently shortened the QTc interval and normalized the repolarization T-wave pattern in five LQT3 patients with SCN5A: DeltaKPQ mutation. DeltaKPQ is associated with repetitive reopening of the $\mathrm{Na}^{+}$channel and prolonged inward current. This dominant inward current is manifested on the ECG as QT interval prolongation. This preliminary study indicates that low-dose flecainide is a promising therapeutic agent for LQTS patients with the SCN5A: DeltaKPQ $\mathrm{Na}^{+}$channel mutation.

Some researchers have wondered if LQT3 syndrome and $\mathrm{BrS}$ are two aspects of the same disease. It is believed that both result in opposite molecular effects: BrS mutations cause reduced $\mathrm{Na}^{+}$current, while LQT3 mutations are associated with a gain of function. The effects of class I antiarrhythmic drugs have been used to differentiate these diseases. Intravenous flecainide is used as a test to unmask the electrocardiographic phenotype of $\mathrm{BrS}$. On the other hand, on the basis of experimental and clinical studies, the possibility that some drugs act as a gene-specific therapy in this disorder by contrasting the effect of mutations in LQT3 has been explored. Recent evidence shows that phenotypic overlap may exist between BrS and LQT3. One large family with a SCN5A mutation and a "mixed" ECG pattern (prolonged QT interval and ST-segment elevation) has been reported. Moreover, recent data has shown that the flecainide test may elicit STsegment elevation in some LQT3 patients. The presence of "intermediate" phenotypes highlights a remarkable heterogeneity suggesting that clinical features may depend upon a single mutation. Only an in-depth understanding 
of the genotype-phenotype correlation will allow both the determination of an individual patient's risk and the development of guidelines for clinical management.

Defects of the SCN5A gene encoding the cardiac sodium channel $\alpha$-subunit are associated with both the LQT3 subtype of long-QT syndrome and BrS.

One previously described SCN5A mutation (1795insD) in the $\mathrm{C}$ terminus results in a clinical phenotype combining QT prolongation and ST segment elevation, indicating a close interrelationship between the two disorders. Rivolta et $\mathrm{al}^{76}$ provide additional evidence that these two disorders are closely related. They report the analysis of two novel mutations on the same codon, Y1795C (LQT3) and Y1795H (BS), expressed in HEK 293 cells and characterized using whole-cell patch clamp procedures. The authors find marked and opposite effects on channel gating consistent with the activity associated with the cellular basis of each clinical disorder. Y1795H speeds and Y1795C slows the onset of inactivation. The $\mathrm{Y} 1795 \mathrm{H}$, but not the Y1795C mutation causes a marked negative shift in the voltage dependence of inactivation, and neither mutation affects the kinetics of the recovery from inactivation. Both mutations increase the expression of sustained sodium channel activity compared with wild type (WT) channels, although this effect is most pronounced for the Y1795C mutation, and both mutations promote entrance into an intermediate or a slowly developing inactivated state. The way in which the C-terminal tail of the cardiac sodium channel controls channel gating illustrates how subtle changes in channel biophysics can have significant and distinct effects in human disease, and, additionally, provides further evidence of the close interrelationship between BrS and LQT3 at the molecular level.

Bezzina et $\mathrm{al}^{77}$ have screened the SCN5A gene in a large 8-generation kindred characterized by a high incidence of nocturnal sudden death, and QT-interval prolongation and the "Brugada ECG" occurring in the same subjects. An insertion of 3 nucleotides (TGA) at position 5537, predicted to cause an insertion of aspartic acid (1795insD) in the C-terminal domain of the protein, was linked to the phenotype identified in all ECG tracings of affected family members. ECGs were obtained from 79 adults with a defined genetic status (carriers, $n$ $=43$; non carriers, $\mathrm{n}=36$ ). In affected individuals, $\mathrm{PR}$ intervals, QRS durations and QT intervals were prolonged ( $\mathrm{P}<0.0001$ for all parameters). ST segment elevation in the right precordial leads is present as well $(\mathrm{P}<0.0001)$. Twenty-five family members died suddenly, 16 of them during the night.

Expression of wild-type and mutant sodium channels in Xenopus oocytes revealed that the 1795insD mutation gives rise to a $7.3 \mathrm{mV}$ negative shift of the steadystate inactivation curve and an $8.1 \mathrm{mV}$ positive shift of the steady-state activation curve.

The functional consequence of both shifts is likely to be a reduced $\mathrm{Na}^{+}$current during the upstroke of the AP. LQT3 and BrS are allelic disorders but may also share a common genotype. The balance between therapeutic and adverse effects from sodium channel blockade by antiarrhythmic compounds may be shifted by subtle alterations in sodium channel function.
Sodium channel blockers amplify existing $\mathrm{INa}^{+}$ and possibly other ion channel defects, with a potency inversely proportional to the rate of dissociation of the drug from the $\mathrm{Na}^{+}$channel, thus causing a prominent elevation of the ST segment (observed in the $\mathrm{V}_{2}$ or $\mathrm{V}_{3}$ leads under baseline conditions, it was greater in the Brugada patients than in control patients) and, in some cases, prolonged QRS duration has occurred in patients with BrS.

A patient with idiopathic VF and a normal ECG or suspected intermittent variation should be given ajmaline, procainamide or flecainide. A 12-lead ECG must be done previous to and after administering the drug. In $0.5 \%$ of cases VF might be provoked. Positive cases are those where a typical electrocardiographic pattern is evident. In these cases the patient should undergo electrophysiological study in order to measure H-V. The pharmacological test for family members is indicated. Asymptomatic carriers of $\mathrm{BrS}$ should be periodically submitted to 24-hour Holter monitoring ${ }^{78}$.

Animal models have shown that class I antiarrhythmic drugs increase the sodium channel number as much as three-fold ${ }^{79}$. This is one explanation why class I drugs could increase late incidence of SCD after myocardial infarction ${ }^{8-81}$

The expression of sodium channels is dynamic and fluctuates over relatively brief time intervals depending on an individual's exposure to these drugs.

It seems that this channel is not directly influenced by neurotransmitter, $\beta$-adrenergic, $\alpha$-adrenergic or muscarinic cholinergic drugs. $\beta$-blockers may decrease the sodium channel density, leaving cell membranes less excitable and therefore less prone to VF and diminishing post-infarction risk of SCD.

Low $\mathrm{pH}$ decreases both the association and dissociation rates of drugs with the sodium channel. Only when low $\mathrm{pH}$ is combined with membrane depolarization is there a net increase in blockage produced by local anesthetic-class drugs.

Tetrodotoxin and local anesthetics block the two types of $\mathrm{Na}^{+}$channels, thereby diminishing the rate of rise of phase 0 and shortening the APD ${ }^{13}$.

Free polyunsaturated fatty acids (PUFAs) inhibit sarcolemmal sodium channels and reduce cytosolic $\mathrm{Ca}^{2+82}$. PUFAs do not appear to upregulate the $\mathrm{Na}^{+}$channel number. Polyunsaturated fatty acids can prevent fatal cardiac arrhythmias because they increase the threshold potential to $50 \%$ and decrease the Relative Refractory Period (RRP) of $\mathrm{AP}^{83}$ (In this period, a strong stimulus can elicit a response, but the timing will be out of sync with the rest of the heart and arrhythmias can occur).

The cardiac sodium channel protein is a multimeric complex consisting of an $\alpha$ and an auxiliary protein $\beta$-subunit: $\beta-1$ and $\beta$-2, with molecular weights of 23 and $21 \mathrm{kDa}$ respectively. The functional role of the $\beta-1$ subunit in the heart is uncertain and there is no evidence of the expression of $\beta-2$ in myocytes.

In $\mathrm{BrS}$, cardiac sodium channel dysfunction is aggravated by the $\beta-1$ subunit ${ }^{84}$. These authors characterize the altered effects of a human $\beta$-1-subunit $(\mathrm{h} \beta(1))$ on the heterologously expressed hH1 mutation (T1620M) previously associated with IVF. It is suggested that coexpres- 
sion of $\mathrm{h} \beta$ (1) exposes a more severe functional defect that results in a greater overlap in the relationship between channel inactivation and activation (window current) in T1620M, which is proposed to be a potential pathophysiological mechanism of IVF in vivo. One possible explanation for this finding is an altered $\alpha-\beta(1)$-subunit association in the mutation.

The biophysical properties of the SCN5A mutation T1620M associated with BrS were examined for defects in intermediate inactivation (I:(M)), a gating process in $\mathrm{Na}^{+}$ channels with kinetic features intermediate between fast and slow inactivation ${ }^{85}$. Cultured mammalian cells expressing $\mathrm{T} 1620 \mathrm{M} \mathrm{Na}^{+}$channels in the presence of the human $\beta-1$ subunit exhibit enhanced intermediate inactivation at both $22^{\circ} \mathrm{C}$ and $32^{\circ} \mathrm{C}$ compared with wild-type recombinant human heart $\mathrm{Na}^{+}$channels (WT-hH1). BrS is caused, in part, by functionally reduced sodium current in the myocardium due to an increased proportion of sodium channels that enter the I:(M) state. This phenomenon may contribute significantly to arrhythmogenesis in patients with $\mathrm{BrS}$.

Postema et al. ask: Do we really understand what's going on? Long-QT syndrome, BrS, and conduction disease may be caused by mutations in the cardiac sodium channel gene SCN5A, and from the ECG one can already presume either a gain- or a loss-of-function defect. The authors described a family harboring 2 SCN5A mutations: the DeltaKPQ mutation, the "classical" gain-of-function mutation associated with LQT3, and the I1660V mutation, a loss-of-function mutation associated with BrS. However, they were surprised by the result of genetic testing in this family. One son who carried the DeltaKPQ mutation but not the $11660 \mathrm{~V}$ mutation did not show the expected Long-QT phenotype but, unexpectedly, showed a conduction disease/Brugada phenotype ${ }^{86}$.

\section{The role of mitochondria in Brugada Syndrome}

Pyridine nucleotides regulate the cardiac $\mathrm{Na}^{+}$current (INa) through generation of reactive oxygen species. Liu et $\mathrm{al}^{87}$ investigated the source of reactive oxygen species induced by elevated NADH. Nicotinamide adenine dinucleotide, abbreviated $\mathrm{NAD}^{+}$, is a coenzyme found in all living cells. The compound is a dinucleotide, since it consists of two nucleotides joined through their phosphate groups, with one nucleotide containing an adenine base and the other containing nicotinamide.

In metabolism, $\mathrm{NAD}^{+}$is involved in redox reactions, carrying electrons from one reaction to another. The coenzyme is, therefore, found in two forms in cells: $\mathrm{NAD}^{+}$is an oxidizing agent - it accepts electrons from other molecules and becomes reduced. This reaction forms $\mathrm{NADH}$, which can then be used as a reducing agent to donate electrons. These electron transfer reactions are the main function of $\mathrm{NAD}^{+}$. However, it is also used in other cellular processes, the most notable one being a substrate of enzymes that add or remove chemical groups from proteins, in posttranslational modifications. Because of the importance of these functions, the enzymes involved in $\mathrm{NAD}^{+}$metabolism are targets for drug discovery.

In human embryonic kidney (HEK) cells stably expressing the cardiac $\mathrm{Na}^{+}$channel, the decrease of $\mathrm{I}_{\mathrm{Na}}$ induced by cytosolic NADH application (100 mumol/L) was reversed by mitoTEMPO, rotenone, malonate, DIDS (4'-diisothiocyanatostilbene-2,2'-disulfonic acid), PK11195, and 4'-chlorodiazepam, a specific scavenger of mitochondrial superoxide and inhibitors of the mitochondrial complex I, complex II, voltage-dependent anion channels, and benzodiazepine receptor, respectively. Anti-mycin A, a complex III inhibitor known to generate reactive oxygen species, decreased INa. This effect was blocked by NAD $(+)$, forskolin, or rotenone. Inhibitors of complex IV, nitric oxide synthase, the NADPH oxidases, xanthine oxidases, the mitochondrial permeability transition pore, and the mitochondrial ATP-sensitive $\mathrm{K}(+)$ channel did not change the $\mathrm{NADH}$ effect on INa. Analogous results were observed in cardiomyocytes. Rotenone, mitoTEMPO, and 4'-chlorodiazepam also blocked the mutant A280V GPD1-L (glycerol-3-phosphate dehydrogenase 1-like) effect on reducing $\mathrm{INa}$, indicating a role for mitochondria in $\mathrm{BrS}$ caused by this mutation. Fluorescent microscopy confirmed mitochondrial reactive oxygen species generation with elevated $\mathrm{NADH}$ and reactive oxygen species inhibition by NAD $(+)$. The authors conclude that altering the oxidized to reduced NAD $(\mathrm{H})$ balance can activate mitochondrial reactive oxygen species production, leading to reduced INa. This signaling cascade may help explain the link between altered metabolism, conduction block, and arrhythmic risk ${ }^{87,88}$.

\section{FINAL CONSIDERATIONS}

We think that this review contributes in a playful, clear and original manner to understanding the significance of the sodium channel in the study of heart functioning, mainly in relation to conductibility and dromotropism and the different phenotypes subsequent to the SCN5A gene mutations, in the field of Health Sciences. In spite of this being a review paper, it allows to understand the basic electrophysiology and clinical consequences of genetic mutations.

\section{ACKNOWLEDGEMENTS}

We thank the students of Design of Studies and Scientific Writing Laboratory at the ABC School of Medicine, Santo André, Sao Paulo, Brazil; Dr John Godleski (Full professor at Harvard University - Harvard Medical School and Harvard T.H. Chan School of Public Health), and Alex Buggs Carll (Visiting Scientist at Harvard T.H. Chan School of Public Health, Boston, MA, US) for reception. Thank you so much for providing us with such a great opportunity

Conflict of interest: The authors declare that they have no conflict of interest.

Author Contributions: Conceived and designed the experiments: PérezRiera AR, Raimundo RD, Abreu LC. Performed the experiments: Pérez-Riera AR, Abreu LC, Analyzed the data: Pérez-Riera AR, Raimundo RD, Abreu LC. Contributed analysis tools: Pérez-Riera AR, Raimundo RD, Abreu LC. Wrote the paper: Pérez-Riera AR, Raimundo RD, Watanabe RA, Abreu LC. Read and approved the last version of the manuscripts: Pérez-Riera AR, Raimundo RD, Watanabe RA, Abreu LC.

Funding: There was no funding for the development of research. 


\section{REFERENCES}

1. Herfst LJ, Rook MB, Jongsma HJ. Trafficking and functional expression of cardiac Na (+) channels. J Mol Cell Cardiol. 2004;36(2):185-90. DOI: http://dx.doi.org/10.1016/j.yjmcc.2003.11.014

2. Swif F, Sjaastad I, Sejersted OM. Does altered regulation of Na+ cause reduced myocardial contractility in heart failure? Tidsskr Nor Laegeforen. 2003;123(21):3036-40.

3. Noda M, Ikeda T, Kayano T, Suzuki H, Takeshima H, Kurasaki M, et al. Existence of distinct sodium channelmessenger RNAs in rat brain. Nature. 1986;320(6058):188-92. DOI: http://dx.doi. org/10.1038/320188a0

4. Makielski JC, Sheets MF, Hanck DA, January CT, Fozzard HA. Sodium current in voltage clamped internally perfused canine cardiac Purkinje cells. Biophys. 1987; 52(1):1-11. DOI: http://dx.doi.org/10.1016/S00063495(87)83182-X

5. Patlak JB, Ortiz M. Slow current through single sodium channels of adult rat heart. J Gen Physiol. 1985;86(1):89-104. DOI: http://dx.doi.org/10.1085/jgp.86.1.89

6. Lederew WJ. Regulation and function of adenosine triphosphate-sensitive potassium channels in the cardiovascular system. In: Zipes DP, Jalife J. Cardiac Electrophysiology from Cell to Bedside. ed. 2, Philadelphia: WB Saunders; 1995.

7. Wang Q1, Shen J, Splawski I, Atkinson D, Li Z, Robinson JL, et al. SCN5A mutations associated with an inherited cardiac arrhythmia, long QT syndrome. Cell. 1995;80(5):805-11. DOI: http://dx.doi.org/10.1016/00928674(95)90359-3

8. Hodgkin AL, Huxley AF. A quantitative and is application to conduction and excitation in nerve. $\mathrm{J}$ Physiol 1952;117:500-44.

9. Wu SN. Simulations of the cardiac action potential based on the Hodgkin-Huxley kinetics with the use of Microsoft Excel spreadsheets. Chin J Physiol. 2004;47(1):15-22.

10. Misuiye T, Noma A. Inactivation of cardiac Na+ channel simply through open states as revealed by singlechannel analysis in guinea pig ventricular myocytes. Jpn J Physiol. 2002;52(2):457-69.

11. Xiao Y, Tang J, Yang Y, Wang M, Hu W, Xie J, et al. Jingzhaotoxin-III, a novel spider toxin inhibiting activation of voltage-gated sodium channel in rat cardiac myocytes. J Biol Chem. 2004;279(25):26220-6. DOI: http:// dx.doi.org/10.1074/jbc.M401387200

12. Fozzard HA, Hanck DA. Structure and function of voltage-dependent sodium channels: comparison of brain Il and cardiac isoforms. Physiol Rev. 1996;76(3):887-960.

13. Ragsdale DS, McPhee JC, Scheuer T, Catterall WA. Molecular determinants of state-dependent block of $\mathrm{Na}^{+}$ channels by local anesthetics. Science. 1994;265(5179):1724-8.

14. Wang SY, Mitchell J, Moczydlowski E, Wang GK. Block of inactivation-deficient Na+ channels by local anesthetics in stably transfected mammalian cells: evidence for drug binding along the activation pathway. $J$ Gen Physiol. 2004;124(6):691-701. DOI: http://dx.doi.org/10.1085/jgp.200409128

15. Wang Q, Li Z, Shen J, Keating MT. Genomic organization of the human SCN5A gene encoding the cardiac sodium channel. Genomic. 1996;34(1):9-16. DOI: http://dx.doi.org/10.1006/geno.1996.0236

16. Malhotra JD, Thyagarajan V, Chen C, Isom LL. Tyrosine-phosphorylated- and nonphosphorylated-sodium channel $\beta-1$ subunits are differentially localized in cardiac myocytes. J Biol Chem. 2004;279(39):40748-54. DOI: http://dx.doi.org/10.1074/jbc.M407243200

17. Malhotra JD, Kazen-Gillespie K, Hortsch M, Isom LL. Sodium channel beta subunits mediate homophilic cell adhesion and recruit ankyrin to points of cell-cell contact. J Biol Chem. 2000;275(15):11383-8. DOI: http:// dx.doi.org/10.1074/jbc.275.15.11383

18. Malhotra JD, Koopmann MC, Kazen-Gillespie KA, Fettman N, Hortsch M, Isom LL. Structural requirements for interaction of sodium channel beta 1 subunits with ankyrin. J Biol Chem. 2002; 277(29):26681-8. DOI: http://dx.doi.org/10.1074/jbc.M202354200

19. Ragsdale DS, McPhee JC, Scheuer T, Catterall WA. Common molecular determinants of local anesthetic, antiarrhythmic, and anticonvulsivant block of voltage-gated Na+ channels. Proc Natl Acad Sci USA. 1996;93(17):9270-5.

20. Rolf S, Bruns HJ, Wichter T, Kirchhof $P$, Ribbing M, Wasmer K, et al. The ajmaline challenge in Brugada syndrome: diagnostic impact, safety, and recommended protocol. Eur Heart J. 2003;24(12):1104-12. DOI: http://dx.doi.org/10.1016/S0195-668X(03)00195-7

21. Scherr D, Brunner G, Kaufmann P, Lercher P, Lueger A, Rotman B, et al. Aborted sudden death in a patient with a structurally normal heart: the Brugada syndrome. Intensive Care Med. 2002;28(6):789-92. DOI: http:// dx.doi.org/10.1007/s00134-002-1300-z

22. Brugada R, Brugada J, Antzelevitch C, Kirsch GE, Potenza D, Towbin JA, et al. Sodium channel blockers identify risk for sudden death in patients with ST-segment elevation and right bundle branch block but structurally normal hearts. Circulation. 2000;101(5):510-15. DOI: http://dx.doi.org/10.1161/01.CIR.101.5.510

23. Brugada J, Brugada R, Brugada P. Brugada syndrome Arch Mal Coeur Vaiss. 1999; 92(7):847-50.

24. Schmidt T, Gerckens U, Ortmeyer D, Bootsveld A, Lampe E, Grube E. Brugada syndrome or ARVD (arrhythmogenic right ventricular dysplasia) or both? Significance and value of right precordial ECG changes. Z Kardiol. 2002;91(5):416-22.

25. Peters S, Trummel M, Denecke S, Koehler B. Results of ajmaline testing in patients with arrhythmogenic right ventricular dysplasia-cardiomyopathy. Int J Cardiol. 2004; 95(2-3):207-10. DOI: http://dx.doi.org/10.1016/j. ijcard.2003.04.032

26. McKenna WJ, Thiene G, Nava A, Fontaliran F, Blomstrom-Lundqvist C, Fontaine G, et al. Diagnosis of arrhythmogenic right ventricular dysplasia/cardiomyopathy. Task Force of the Working Group Myocardial and Pericardial Disease of the European Society of Cardiology and of the Scientific Council on Cardiomyopathies 
of the International Society and Federation of Cardiology. Br Heart J. 1994;71(3):215-8.

27. Chiale PA, Przybylski J, Laiño RA, Halpern MS, Sánchez RA, Gabrieli A, et al. Electrocardiographic changes evoked by ajmaline in chronic Chagas'disease without manifest myocarditis. Am J Cardiol. 1982;49(1):1420. DOI: http://dx.doi.org/10.1016/0002-9149(82)90271-5

28. Bertaglia E, Michieletto M, Spedicato L, Pascotto P. Right bundle branch block, intermittent ST segment elevation and inducible ventricular tachycardia in an asymptomatic patient: an unusual presentation of the Brugada syndrome? G Ital Cardiol. 1998;28(8):893-8.

29. Brugada J, Brugada P. What to do in patients with no structural heart disease and sudden arrhythmic death? Am J Cardiol. 1996;78(5A):69-75.

30. Eckardt L, Kirchhof P, Johna R, Breithardt G, Borggrefe M, Haverkamp W. Transient local changes in right ventricular monophasic action potentials due to ajmaline in a patient with Brugada syndrome. J Cardiovasc Electrophysiol. 1999; 10(7):1010-5.

31. PinarBermúdezE, García-AlberolaA, MartínezSánchezJ, SánchezMuñozJJ, Valdés ChávarriM. Spontaneous sustained monomorphic ventricular tachycardia after administration of ajmaline in a patient with Brugada syndrome. Pacing Clin Electrophysiol. 2000;23(3):407-9. DOI: http://dx.doi.org/10.1111/j.1540-8159.2000. tb06771.x

32. Wendt DJ, Starmer CF, Grant AO. pH dependence of kinetics and steady-state block of cardiac sodium channel by lidocaine. Am J Physiol. 1993;264(5 Pt 2):H1588-98.

33. Shiraishi H1, Hyogo M, Ishibashi K, Urao N, Tsukamoto M, Keira N, et al. Rate-dependent QRS prolongation during exercise testing associated with hyperkalemia. J Electrocardiol. 2004;37(3):241-5. DOI: http://dx.doi. org/10.1016/j.jelectrocard.2004.02.006

34. Khan IA, Nair CK. Brugada and long QT-3 syndromes: two phenotypes of the sodium channel disease. Ann Noninvasive Electrocardiol.2004;9(3):280-9. DOI: http://dx.doi.org/10.1111/j.1542-474X.2004.93533.x

35. Wang GK, Russell C, Wang SY. Mexiletine block of wild-type and inactivation-deficient human skeletal muscle hNav1.4 Na+ channels. J Physiol. 2004;554(Pt3):621-33. DOI: http://dx.doi.org/10.1113/jphysiol.2003.054973

36. Shimizy W, Aiba T, Antzelevitch C. Specific therapy based on the genotype and cellular mechanism in inherited cardiac arrhythmias. Long QT syndrome and Brugada syndrome. Curr Pharm Des. 2005;11(12):1561-72.

37. Chang CC, Acharfi S, Wu MH, Chiang FT, Wang JK, Sung TC, et al. A novel SCN5A mutation manifests as a malignant form of long QT syndrome with perinatal onset of tachycardia/bradycardia. Cardiovasc Res. 2004;64(2):268-78. DOI: http://dx.doi.org/10.1016/j.cardiores.2004.07.007

38. Ramos E, O'leary ME. State-dependent trapping of flecainide in the cardiac sodium channel. J Physiol. 2004;560(Pt 1):37-49. DOI: http://dx.doi.org/10.1113/jphysiol.2004.065003

39. Windle JR, Geletka RC, Moss AJ, Zareba W, Atkins DL. Normalization of ventricular repolarization with flecainide in long QT syndrome patients with SCN5A: DeltaKPQ mutation. Ann Noninvasive Electrocardiol. $2001 ; 6(2): 153-8$.

40. Ten Harkel ADJ, Wotsenburg M, Jong PL, Wilde AAM. Wijman LJM. Efficacy of an implantable cardioverterdefibrillator in a neonate with LQT3 associated arrhythmias. Europace. 2005;7(1):77-84. DOI: http://dx.doi. org/10.1016/j.eupc.2004.09.007

41. Liu H, Clancy C, Cormier J, Kass R. Mutations in cardiac sodium channels: clinical implications. Am J Pharmacogenomics. 2003;3(3):173-9. DOI: http://dx.doi.org/10.2165/00129785-200303030-00003

42. Ikeda N, Singh BN, Davis LD, Hauswirth O. Effects of flecainide on the electrophysiologic properties of isolated canine and rabbit myocardial fibers. J Am Coll Cardiol. 1985;5(2 Pt 1):303-10. DOI: http://dx.doi. org/10.1016/S0735-1097(85)80051-6

43. Wang ZG, Pelletier LC, Talajic M, Nattel S. Effects of flecainide and quinidine on human atrial action potentials. Role of rate-dependence and comparison with guinea pig, rabbit, and dog tissues. Circulation. 1990;82(1):274-83.

44. Tian XL, Yong SL, Wan X, Wu L, Chung MK, Tchou PJ, et al. Mechanisms by which SCN5A mutation N1325S causes cardiac arrhythmias and sudden death in vivo. Cardiovasc Res. 2004;61(2):256-67. DOI: http://dx.doi.org/10.1016/j.cardiores.2003.11.007

45. Priori SG, Napolitano C. Genetic defects of cardiac ion channels. The hidden substrate for torsades de pointes. Cardiovasc Drugs Ther. 2002;16:89. DOI: http://dx.doi.org/10.1023/A:1015793113771

46. Noebels JL. How a Sodium Channel Mutation Causes Epilepsy. Epilepsy Curr. 2003;3(2):70-1. DOI: http:// dx.doi.org/10.1046/j.1535-7597.2003.03214.x

47. Moric-Janiszewska E, Herbert E, Cholewa K, Filipecki A, Trusz-Gluza M, Wilczok T. Mutational screening of SCN5A linked disorders in Polish patients and their family members. J Appl Genet. 2004;45(3):383-90.

48. Viswanathan PC, Balser JR. Inherited sodium channelopathies: a continuum of channel dysfunction. Trends Cardiovasc Med. 2004;14(1):28-35. DOI: http://dx.doi.org/10.1016/j.tcm.2003.10.001

49. Napolitano C, Rivolta I, Priori SG. Cardiac sodium channel diseases. Clin Chem Lab Med. 2003;41(4):43944. DOI: http://dx.doi.org/10.1515/CCLM.2003.066

50. Antzelevitch C. Molecular biology and cellular mechanisms of Brugada and long QT syndromes in infants and young children. J Electrocardiol. 2001;34(Suppl):177-81. DOI: http://dx.doi.org/10.1054/jelc.2001.0340320

51. Baroudi G, Napolitano C, Priori SG, Del Bufalo A, Chahine M. Loss of function associated with novel mutations of the SCN5A gene in patients with Brugada syndrome. Can J Cardiol. 2004;20(4):425-30.

52. Valdivia CR, Tester DJ, Rok BA, Porter CB, Munger TM, Jahangir A, et al. A trafficking defective, Brugada syndrome-causing SCN5A mutation rescued by drugs. Cardiovasc Res. 2004;62(1):53-62. DOI: http://dx.doi. org/10.1016/j.cardiores.2004.01.022

53. Ackerman MJ, Siu BL, Sturner WQ, Tester DJ, Valdivia CR, Makielski JC, et al. Postmortem molecular analysis of SCN5A defects in sudden infant death syndrome. JAMA. 2001;286(18):2264-9. DOI: http://dx.doi. org/10.1001/jama.286.18.2264 
54. Wedekind H, Smits JP, Schulze-Bahr E, Arnold R, Veldkamp MW, Bajanowski T, et al. De novo mutation in the SCN5A gene associated with early onset of sudden infant death. Circulation. 2001;104(10):1158-64. DOI: http://dx.doi.org/10.1161/hc3501.095361

55. Vatta M, Dumaine R, Varghese G, Richard TA, Shimizu W, Aihara N, et al. Genetic and biophysical basis of sudden unexplained nocturnal death syndrome (SUNDS), a disease allelic to Brugada syndrome. Hum Mol Genet. 2002;11(3):337-45. DOI: http://dx.doi.org/10.1093/hmg/11.3.337

56. Akai J, Makita N, Sakurada H, Shirai N, Ueda K, Kitabatake A, et al. A novel SCN5A mutation associated with idiopathic ventricular fibrillation without typical ECG findings of Brugada syndrome. FEBS Lett. 2000; 479(1-2):29-34.

57. Tan HL, Bink-Boelkens MT, Bezzina CR, Viswanathan PC, Beaufort-Krol GC, van Tintelen PJ, et al. A sodiumchannel mutation causes isolated cardiac conduction disease. Nature. 2001;409(6823):1043-7. DOI: http:// dx.doi.org/10.1038/35059090

58. Baroudi G, Chahine M. Biophysical phenotypes of SCN5A mutations causing long QT and Brugada syndromes. FEBS Lett. 2000;487(2):224-8. DOI: http://dx.doi.org/10.1016/S0014-5793(00)02360-7

59. Shirai N, Makita N, Sasaki K, Yokoi H, Sakuma I, Sakurada H, et al. A mutant cardiac sodium channel with multiple biophysical defects associated with overlapping clinical features of Brugada syndrome and cardiac conduction disease. Cardiovasc Res. 2002;53(2):348-54. DOI: http://dx.doi.org/10.1016/S00086363(01)00494-1

60. Weiss R, Barmada MM, Nguyen T, Seibel JS, Cavlovich D, Kornblit CA, et al. Clinical and molecular heterogeneity in the Brugada syndrome: a novel gene locus on chromosome 3. Circulation. 2002;105(6):70713. DOI: http://dx.doi.org/10.1161/hc0602.103618

61. Grant AO, Carboni MP, Neplioueva V, Starmer CF, Memmi M, Napolitano C, et al. Long QT syndrome, Brugada syndrome, and conduction system disease are linked to a single sodium channel mutation. J Clin Invest. 2002;11098):1201-9. DOI: http://dx.doi.org/10.1172/JCl15570

62. Lupoglazoff JM, Denjoy I, Cheav T, Berthet M, Extramiana F, Cauchemez B, et al. Homozygotous mutation of the SCN5A gene responsible for congenital long QT syndrome with 2/1 atrioventricular block. Arch Mal Coeur Vaiss. 2002;95(5):440-6.

63. Rossenbacker T, Carroll SJ, Liu H, Kuipéri C, de Ravel TJ, Devriendt K, et al. Novel pore mutation in SCN5A manifests as a spectrum of phenotypes ranging from atrial flutter, conduction disease, and Brugada syndrome to sudden cardiac death. Heart Rhythm. 2004;1(5):610-15. DOI: http://dx.doi.org/10.1016/j. hrthm.2004.07.001

64. Smits JPP, Koopmann TT, Wilders R, Veldkamp MW, Opthof T, Bhuiyan ZA, et al. A mutation in the human cardiac sodium channel $(\mathrm{E} 161 \mathrm{~K})$ contributes to sick sinus syndrome, conduction disease and Brugada syndrome in two families. J Mol Cell Cardiol. 2005;3896):969-81. DOI: http://dx.doi.org/10.1016/j.yjmcc.2005.02.024

65. Dworakoska B, Dolowy K. Ion channels-related diseases. Acta Biochim Pol. 2000; 47(3):685-703.

66. Kapur J. Sodium Channel Mutations in GEFS (+) Produce Persistent Inward Current. Epilepsy Curr. 2002;2(5):149-50. DOI: http://dx.doi.org/10.1046/j.1535-7597.2002.00055.x

67. Clancy CE, Rudy Y. Na (+) channel mutation that causes both Brugada and long-QT syndrome phenotypes: a simulation study of mechanism. Circulation. 2002; 105910):1208-13. DOl: http://dx.doi.org/10.1161/ hc1002.105183

68. Abriel H, Wehrens XH, Benhorin J, Kerem B, Kass RS. Molecular pharmacology of the sodium channel mutation D1790G linked to the long-QT syndrome. Circulation. 2000;102(8):921-5.

69. Choi JS, Tyrrell L, Waxman SG, Dib-Hajj SD. Functional role of the C-terminus of voltage-gated sodium channel Na(v)1.8. FEBS Lett. 2004; 57291-3):256-60. DOI: http://dx.doi.org/10.1016/j.febslet.2004.07.047

70. Deschenes I, Baroudi G, Berthet M, Barde I, Chalvidan T, Denjoy I, et al. Electrophysiological characterization of SCN5A mutations causing long QT (E1784K) and Brugada (R1512W and R1432G) syndromes. Cardiovasc Res. 2000;46(1):55-65. DOI: http://dx.doi.org/10.1016/S0008-6363(00)00006-7

71. Benett PB, Yazawa K, Makita N, et al. Molecular mechanism for an inherited cardiac arrhythmia. Nature. 1995;376(6542):683-5. DOI: http://dx.doi.org/10.1038/376683a0

72. Balser JR. The cardiac sodium channel: gating function and molecular pharmacology. J Mol Cell Cardiol. 2001;33(4):599-613. DOI: http://dx.doi.org/10.1006/jmcc.2000.1346

73. Tan HL, Kupershmidt S, Zhang R, Stepanovic S, Roden DM, Wilde AA, et al. A calcium sensor in the sodium channel modulates cardiac excitability. Nature.2002;415(6870):442-7. DOI: http://dx.doi.org/10.1038/415442a

74. Bers DM. Macromolecular complexes regulating cardiac ryanodine receptor function. J Mol Cell Cardiol. 2004;37(2):417-29. DOI: http://dx.doi.org/10.1016/j.yjmcc.2004.05.026

75. Shimizu W, Antzelevitch C, Suyama K, Kurita T, Taguchi A, Aihara N, et al. Effect of sodium channel blockers on ST segment, QRS duration, and corrected QT interval in patients with Brugada syndrome. J Cardiovasc Electrophysiol. 2000;11(12):1320-9. DOI: http://dx.doi.org/10.1046/j.1540-8167.2000.01320.x

76. Rivolta I, Abriel H, Tateyama M, Liu H, Memmi M, Vardas P, et al. Inherited Brugada and long QT-3 syndrome mutations of a single residue of the cardiac sodium channel confer distinct channel and clinical phenotypes. J Biol Chem. 2001; 276(33):30623-30. DOI: http://dx.doi.org/10.1074/jbc.M104471200

77. Bezzina C, Veldkamp MW, van Den Berg MP, Postma AV, Rook MB, Viersma JW, et al. A single Na (+) channel mutation causing both long-QT and Brugada syndromes. Circ Res. 1999;85(12):1206-13.

78. Maia IG, Soares MW, Boghossian SH, Sá R. The Brugada syndrome. Outcome of one case. Arq Bras Cardiol. 2000;74(5):43745.

79. Duff HJ, Offord J, West JW, Catterall WA. Class I and IV antiarrhythmic drugs and cytosolic calcium regulate mRNA encoding the sodium channel alpha subunit in rat cardiac muscle. Mol Pharmacol. 1992; 42(4): 570-4.

80. Effect of the antiarrhythmic agent moricizine on survival after myocardial infarction. The Cardiac Arrhythmia Suppression Trial II Investigators. N Engl J Med 1992;327(4):227-33. DOI: http://dx.doi.org/10.1056/ NEJM199207233270403 
81. Echt DS, Liebson PR, Mitchell LB, Peters RW, Obias-Manno D, Barker AH, et al. Mortality and morbidity in patients receiving encainide, flecinide, or placebo. The Cardiac Arrhthmia Supression Trial. N Engl J Med. 1991;324(12):781-8. DOI: http://dx.doi.org/10.1056/NEJM199103213241201

82. Leaf A, Kang JX. Dietary n-3 fatty acids in the prevention of lethal cardiac arrhtymias. Curr Opin Lipidol. 1997;8(1):4-6.

83. Kang JX, Leaf A. Prevention fatal cardiac arrhythmias by polyunsaturated fatty acids. Am J Clin Nutr. 2000;71(1 Suppl): 202S-7.

84. Makita N, Shirai N, Wang DW, Sasaki K, George AL Jr, Kanno M, et al. Cardiac Na (+) channel dysfunction in Brugada syndrome is aggravated by beta (1)-subunit. Circulation. 2000;101:54-60. DOI: http://dx.doi. org/10.1161/01.CIR.101.1.54

85. Wang DW, Makita N, Kitabatake A, Balser JR, George AL Jr. Enhanced Na (+) channel intermediate inactivation in Brugada syndrome. Circ Res. 2000;87(8):E37-43. DOI: http://dx.doi.org/10.1161/01.RES.87.8.e37

86. Postema PG, Mosterd A, Hofman N, Alders M, Wilde AA. Sodium Channelopathies: Do We Really Understand What's Going On? J Cardiovasc Electrophysiol. 2011;22(5):590-3. DOI: http://dx.doi.org/10.1111/j.15408167.2010.01892.x

87. Liu M, Liu H, Dudley SC Jr. Reactive Oxygen Species Originating From Mitochondria Regulate the Cardiac Sodium Channel. Circ Res. 2010;107(8):967-74. DOI: http://dx.doi.org/10.1161/CIRCRESAHA.110.220673

88. Branco AT. The evolution of genetics to genomics. J Hum Growth Dev. 26(1): 28-32. Doi: http://dx.doi. org/10.7322/jhgd.113710

This article is distributed under the terms of the Creative Commons Attribution 4.0 International License (http://creativecommons.org/licenses/by/4.0/), which permits unrestricted use, distribution, and reproduction in any medium, provided you give appropriate credit to the original author(s) and the source, provide a link to the Creative Commons license, and indicate if changes were made. The Creative Commons Public Domain Dedication waiver (http://creativecommons.org/publicdomain/zero/1.0/) applies to the data made available in this article, unless otherwise stated.

\section{Resumo:}

Os mecanismos da excitabilidade celular e de propagação dos sinais elétricos no músculo cardíaco são de grande importância funcional e patológica. O coração é composto por três tipos de músculo: atrial, ventricular e das fibras especializadas excitatórias e condutoras. Do ponto de vista fisiológico e fisiopatológico os estados conformacionais do canal de sódio constitui-se um importante aspecto para o diagnóstico e tratamento de doenças cardíacas. A descrição dos estados funcionais do canal de sódio (fechado, aberto e inativado) e sua estrutura ajudam a compreensão dos processos de regulação cardíaca. Há áreas no músculo cardíaco com diferenciação anatômica e funcional que possuem automatismo submetendo as demais fibras ao seu próprio ritmo. A frequência dessas áreas (marca-passo) pode ser alterada por modificações iônicas, pela temperatura e, especialmente, do sistema autonômico. Já a excitabilidade é a propriedade que tem o miocárdio de reagir quando estimulado. A outra propriedade elétrica é a condutibilidade, que se caracteriza por um processo de condução e ativação, no qual o potencial de ação, pela ei do tudo ou nada, percorre todo o coração. Destaca-se que o relaxamento do coração também é um processo ativo, dependente de gasto energético e de ações iônicas e enzimáticas específicas, destacando o papel dos canais de sódio no processo funcional. Nos aspectos das mutações no gene que codifica o canal rápido de sódio (gene SCN5A), este é responsável por vários fenótipos, tais como a síndrome de Brugada; a fibrilação ventricular idiopática, a miocardiopatia dilatada; a síndrome de repolarização precoce; a fibrilação atrial familiar; a síndrome do QT longo variante 3; as contrações ventriculares ectópicas multifocais originadas nas arborizações de Purkinje; o distúrbio progressivo de condução intraventricular cardíaco (doença de Lenègre); a síndrome da morte súbita do recém-nascido; a síndrome do nódulo sinusal doente; a síndrome da morte súbita noturna inesperada, entre outras alterações do canal de sódio com sobreposições clínicas, as chamadas "overpping". Por fim, parece ser apropriado considerar a "síndrome do canal de sódio" (mutações no gene da subunidade a do canal de sódio, gene SCN5A) como uma entidade clínica única que pode manifestar-se com um amplo espectro de fenótipos e assim, prover um melhor entendimento destas síndromes cardíacas e potencial desfecho para seu tratamento clínico.

Palavras-chave: síndromes arrítmicas, potencial de ação, a despolarização, da condução cardíaca. 